\title{
Quantifying raft proteins in neonatal mouse brain by 'tube-gel' protein digestion label-free shotgun proteomics Hongwei $\mathrm{Yu}^{* \dagger 1}$, Bassam Wakim ${ }^{\dagger 2}$, Man Li1 ${ }^{1,6}$, Brian Halligan 3 , G Stephen Tint ${ }^{4}$ and Shailendra B Patel ${ }^{1,5}$
}

\begin{abstract}
Address: ${ }^{1}$ Division of Endocrinology, Metabolism and Nutrition, Medical College of Wisconsin, Milwaukee, WI 53226, USA, ${ }^{2}$ Department of Biochemistry, Medical College of Wisconsin, Milwaukee, WI 53226, USA, ${ }^{3}$ National Center for Proteomics Research, Biotechnology and Bioinformatics Center, Medical College of Wisconsin, Milwaukee, WI 53226, USA, ${ }^{4}$ Research Service, Department of Veterans Affairs New Jersey Health Care System, East Orange, NJ 07018, USA, and Department of Medicine, UMDNJ-New Jersey Medical School, Newark, NJ 07103-2714, USA, ${ }^{5}$ Department of Veterans Affairs, Clement J. Zablocki Medical Center, Milwaukee, WI 53295, USA and ${ }^{6}$ Qilu Hospital, Shandong University, 44 West Wenhua Road, Jinan, 250012, P. R. China
\end{abstract}

Email: Hongwei Yu* - hyu@mcw.edu; Bassam Wakim - bwakim@mcw.edu; Man Li - manli@mcw.edu; Brian Halligan - halligan@mcw.edu; G Stephen Tint - tintgs@umdnj.edu; Shailendra B Patel - sbpatel@mcw.edu

* Corresponding author †Equal contributors

Published: 24 September 2007

Proteome Science 2007, 5:17 doi:10.1186/1477-5956-5-17

This article is available from: http://www.proteomesci.com/content/5/I/17

This is an Open Access article distributed under the terms of the Creative Commons Attribution License (http://creativecommons.org/licenses/by/2.0), which permits unrestricted use, distribution, and reproduction in any medium, provided the original work is properly cited.

\begin{abstract}
Background: The low concentration and highly hydrophobic nature of proteins in lipid raft samples present significant challenges for the sensitive and accurate proteomic analyses of lipid raft proteins. Elimination of highly enriched lipids and interfering substances from raft samples is generally required before mass spectrometric analyses can be performed, but these procedures often lead to excessive protein loss and increased sample variability. For accurate analyses of the raft proteome, simplified protocols are needed to avoid excessive sample handling and purification steps.
\end{abstract}

Results: We have devised a simple protocol using a 'tube-gel' protein digestion that, when combined with mass spectrometry, can be used to obtain comprehensive and reproducible identification and quantitation of the lipid raft proteome prepared from neonatal mouse brain. Lipid rafts (detergent-resistant membranes using Triton X-100 extraction) prepared from neonatal mouse brain were directly incorporated into a polyacrylamide tube-gel matrix without prior protein separation. After in-gel digestion of proteins, nanospray LC-MS/MS was used to analyze the extracted peptides, and the resulting spectra were searched to identify the proteins present in the sample. Using the standard 'label-free' proteomics approach, the total number of MS/MS spectra for the identified proteins was used to provide a measure of relative protein abundances. This approach was successfully applied to lipid rafts prepared from neonatal mouse brain. A total of 216 proteins were identified: 127 proteins (58.8\%) were predicted to be membrane proteins, or membrane-associated proteins and 175 proteins $(-80 \%)$ showed less than a 2 -fold variation in the relative abundance in replicate samples.

Conclusion: The tube-gel protein digestion protocol coupled with nanospray LC-MS/MS (TubeGeLC-MS/MS) offers a simple and reproducible method for identifying and quantifying the changes of relative abundances in lipid raft proteins from neonatal mouse brain and could become a useful approach for studying lipid raft proteins from various tissues. 


\section{Background}

Lipid rafts are cholesterol- and sphingolipid-enriched specialized structures present in biological membranes [1-5] that can be isolated by various techniques. A common method for the isolation of the rafts is to prepare detergent-resistant membranes (DRMs) by extraction with the nonionic detergent Triton X-100 at cold temperature. Recent interest in lipid rafts arises from observations that some membrane proteins appear to partition preferentially into raft domains, and may require this environment for their biological activity [4,5]. Many previous studies have utilized two-dimensional gel electrophoresis (2DE) for proteomic profiling, but this method is limited by its lower sensitivity and it is often inefficient when analyzing raft proteins. Mass spectrometry (MS) has become a powerful tool for the analysis of complex protein mixtures. Proteomics profiling of either protein mixtures fractionated by $1 \mathrm{DE}$ or unfractionated protein mixtures by protease digestion and LC-MS/MS analysis has become increasingly popular. Peptides are identified by searching the resulting MS/MS spectra against protein sequence databases and protein presence is inferred from peptide presence. This general approach is referred to as 'topdown' or 'shotgun' proteomics. Several studies utilizing 1D gel filtration or in-solution protein digestion, combined with stable isotope labeling or label-free LC-MS/ MS, have successfully profiled the protein composition and abundance in lipid rafts prepared from different biological sources [6-14]. However, quantitation of changes in the raft protein abundance under various experimental circumstances remains a major challenge. A number of technical factors are critical for analytical reliability, such as sample quality, reproducibility of the raft preparations, quality of the chromatography system, and the performance of the mass spectrophotometer. The most pressing problems for lipid raft proteomic investigations are those involving sample preparation and handling. Lipid raft samples prepared by different methods are composed of highly enriched lipids and low concentrations of hydrophobic proteins. Raft preparations also contain many non-proteinaceous substances including exogenous reagents, such as salts, buffers and detergents employed for sample preparation. These highly enriched lipids and non-protein components, or contaminants can often interfere with proteome analysis and their removal is a critical step before any proteome analysis can be performed. Although the low protein concentrations in raft samples do not present a limitation for analysis, methods used for removing lipids and other interfering substances from raft samples can lead to excessive protein loss. Thus, the process of lipid raft preparation suitable for mass spectrometry is a major factor in the variability of data obtained by these powerful proteomic techniques.
For accurate analyses of the raft proteome, a robust protocol avoids excessive purification steps, each of which lead to additional protein losses, is desirable. To avoid protein loss during sample preparation for mass spectrometry, a 'tube-gel' protein digestion protocol was adopted in which the lipid raft samples were directly incorporated into a polyacrylamide tube-gel without electrophoresis [15]. Detergents, lipids and other possible LC-MS/MS interfering materials in the raft samples are eliminated from the gel matrix while proteins are retained in the gel matrix. After the in-gel digestion of proteins, automated nanospray liquid chromatography tandem mass spectrometry (nanospray LC-MS/MS) is used to analyze the extracted peptides for protein identification. This protocol was used to analyze the protein profile of lipid rafts prepared from neonatal mouse brain. Neonatal mouse brain was chosen because there have been few proteomic studies of lipid rafts from neonatal brain [16-21]. Neonatal brain disorders are an important cause of mortality and morbidity contributing to the development of autism, cholesterol biosynthesis disorders, and a myriad of learning and developmental neurological and cognitive disabilities [22-27]. Developmental membrane defects have been postulated as one of the pathophysiological processes in these neonatal brain disorders. Additionally, the higher sterol content in brain tissue presents an additional challenge in preparing lipid raft samples for nanospray LC-MS/MS analysis.

Starting with limited amounts of frozen brain tissue, a total of 216 raft proteins were identified. Among the identified proteins, 127 (58.8\%) were predicted to be plasma membrane (PM) or PM associated proteins including a number of authentic raft and/or GPI and lipid anchoring proteins, receptors, channel proteins, synaptic proteins, kinases, heterotrimeric G protein subunits, and some novel membrane proteins important for neurodevelopment. The major brain raft proteins, reported in previous investigations $[8,18,19,28]$, were also identified as high abundance raft proteins in the present study. An advantage of this method is that it allows for raft proteins to be digested directly, dramatically reducing variations due to sample preparation prior to mass spectrometry. In this study, the standard 'label-free' proteomics approach in which total MS/MS spectral count is utilized to quantify the relative abundance of the identified proteins was used [29]. The results showed that the variations of relative abundance in $\sim 80 \%$ of the identified proteins in replicate samples were less than 2-fold, suggesting that the method is highly reproducible. This approach offers a simple and reproducible protocol for identifying and quantifying changes in the relative abundance of the lipid raft proteins from neonatal mouse brain and could become a useful method for studying lipid raft proteins from various tissues. 


\section{Results and Discussion Characterization of lipid rafts by sucrose density gradient ultracentrifugation}

Biochemical isolation of lipid raft membranes by gradient ultracentrifugation, as well as their subsequent analysis, is a useful and simple method to determine if membrane components are located in raft microdomains. The distributions of total protein, sucrose density, and contents of sterols, sphingomyelin (SM) and ceramide (Cer), as well as the lighting-scattering properties at $620 \mathrm{~nm}$, for each of the sucrose gradient fractions are summarized in Figure 1. Buoyant low density fractions 2-4 (DRMs/rafts) had the greatest light-scattering properties at $620 \mathrm{~nm}$, consistent with a high content of lipids, but the non-raft fractions 811 had little or no absorbance. Conversely, most of the recovered proteins were present in the non-raft fractions and the total protein in the lipid raft fractions was too low to allow for accurate measurement by conventional methods. The lipid raft fractions $2 \sim 4$ were highly enriched in sterols (a mixture composed of $\sim 60 \%$ cholesterol, $\sim 40 \%$ desmosterol, and trace amounts of other sterol precursors such as 7-dehydrodesmosterol and lathosterol), SM, and Cer compared to plasma membranes. Further characterization of the known raft and the non-raft marker proteins in the sucrose gradients was performed by immunoblotting (Figure 2). Known raft proteins, such as caveolin-1 (cav-1), flotillin-1 (flot-1), contactin-1 (Cntn-1), annexin -VI (Anx-VI, Anx6A), GTP-binding protein $\alpha q(\mathrm{G} \alpha q)$, and NAP-22, were present in the low-density fractions (fractions 2 4). Various accepted non-raft markers, such as $\beta$ COP (a Golgi marker), transferrin receptor (TfR) (a nonraft membrane marker protein), $\alpha$-tubulin (a cytoskeletal protein), calnexin (an ER resident membrane protein), and ATP synthase (a mitochondrial protein), were only present in the high-density fractions. Collectively, these results reflect the typical biochemical profiles of lipid rafts from brain tissue $[8,30,31]$.

\section{Analysis of core raft proteome in neonatal mouse brain by TubeGeLC-MSIMS}

The core protein composition of lipid rafts from neonatal mouse brain was determined by using a tube-gel protein digestion coupled with nanospray LC-MS/MS (TubeGeLC-MS/MS) analyses. The major benefit of this modification is that the raft proteins (usually in limiting quantities) are digested in a tube-gel matrix without fractionation and purification. Thus, sample losses are minimized compared to in-gel digestion based on SDS-PAGE.
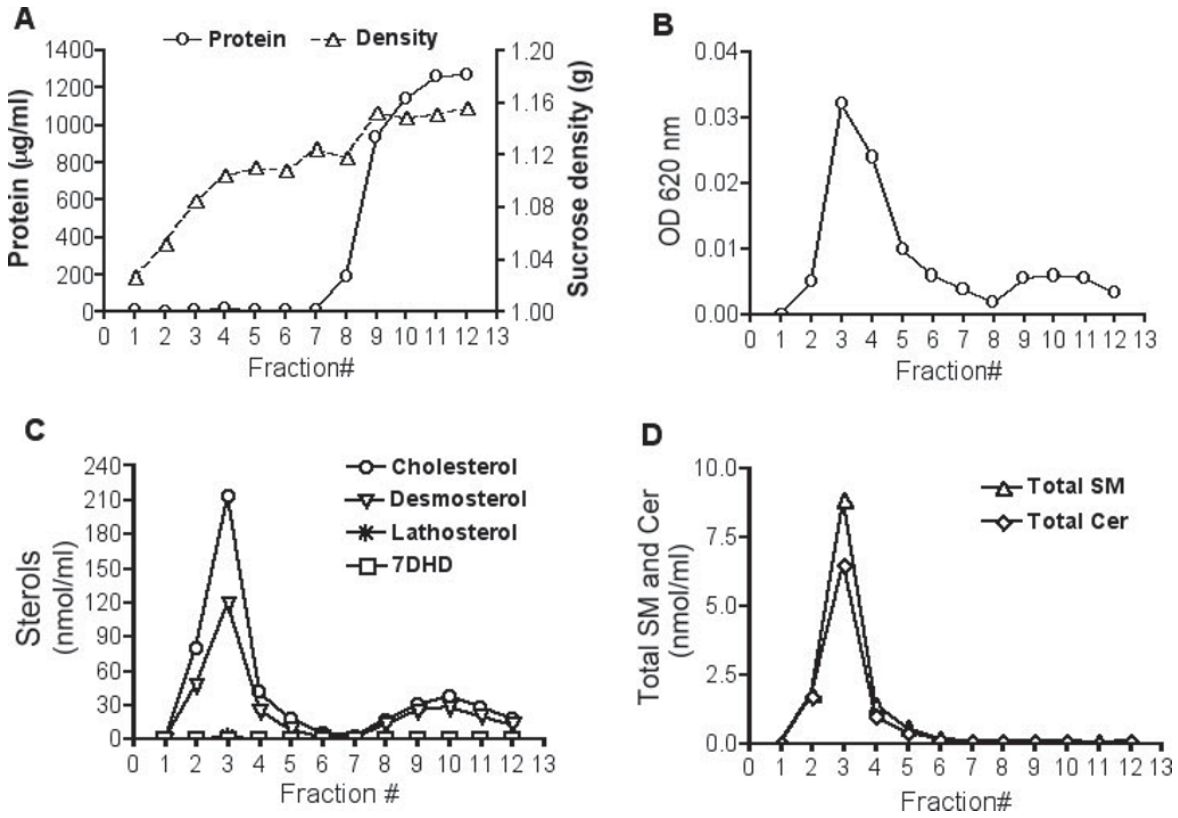

\section{Figure I}

Biochemical characterization of sucrose density gradient fractions of neonatal mouse brain. Panel A shows the distributions of protein and sucrose density in membrane fractions from sucrose gradients of neonatal brain. Panel B shows the light-scattering properties of each fraction by absorbance at $620 \mathrm{~nm}$. The buoyant low density fractions $2 \sim 4$ showed the greatest light-scattering properties at $620 \mathrm{~nm}$, consistent with a high content of lipids. Panel $C$ shows the distribution of sterols (cholesterol, desmosterol, lathosterol, and 7-dehydrodesmosterol (7DHD)) in each fraction from sucrose gradients of neonatal mouse brain and Panel D shows total sphingomyelin (SM) and ceramide (Cer). 


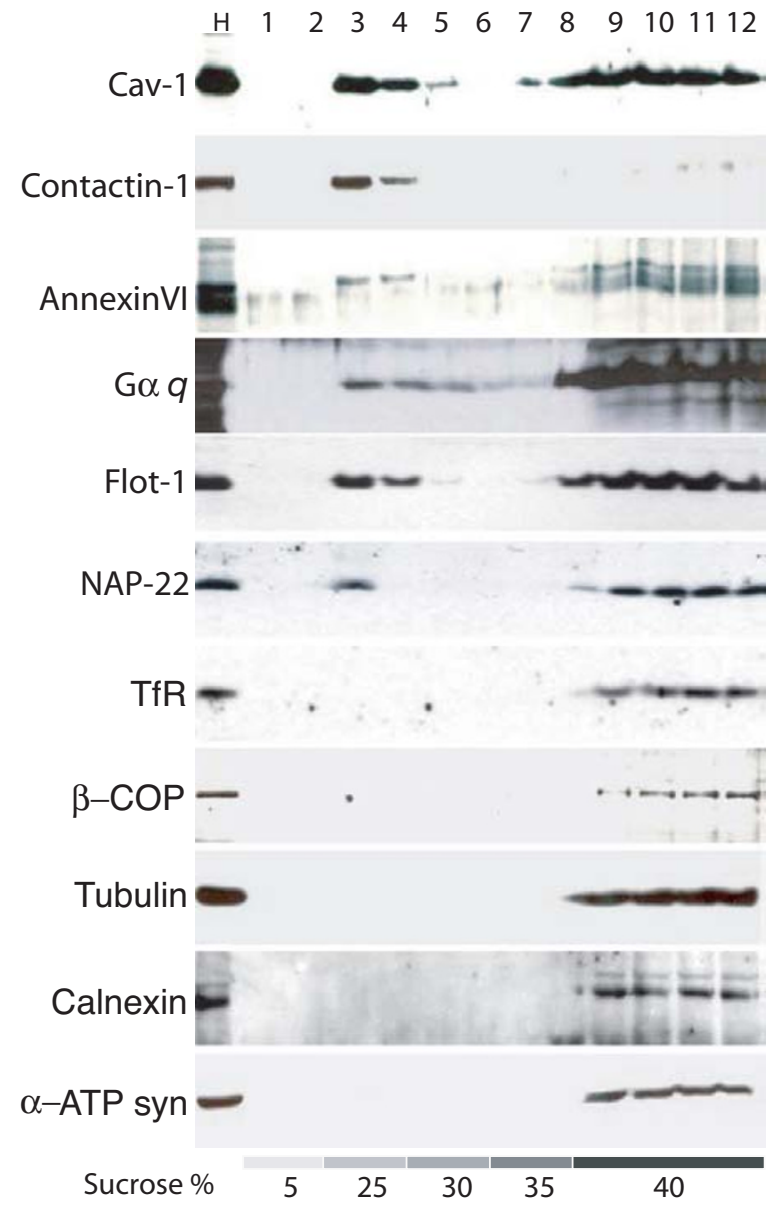

Figure 2

Localization of known raft and non-raft marker proteins in sucrose gradients. Post-nuclear homogenates (PNH) from neonatal brain tissues were extracted using I\% of Triton X-100 (TX) and fractionated in 5-40\% discontinuous sucrose-density gradient as described in Methods.

Twelve fractions of each $1.0 \mathrm{ml}$ were collected from the top to bottom. Twenty $\mu \mathrm{g}$ of $\mathrm{PNH}$ protein $(\mathrm{H})$ and equal $30 \mu \mathrm{l}$ of each fraction of gradient were subjected to immunoblotting with antibodies against indicated proteins.

Moreover, inclusion of detergents (Triton X-100 and SDS. See Methods) can facilitate the effective solubilization and denaturation of hydrophobic lipid raft membrane proteins [32,33]. After proteins are incorporated into the tube-gel, the detergents, lipids and other interfering substances can be efficiently eliminated by extensive washing with acetonitrile prior to protein enzymatic digestion and subsequent nanospray LC-MS/MS analysis, without any significant loss of the proteins that are trapped in the gel matrix [15]. This tube-gel approach has been successfully employed for high throughout mass spectrometric analysis of membrane proteins [15].

Two biological replicates (raft preparations from two neonatal brains), each with two MS technical replicates, were analyzed by TubeGeLC-MS/MS method. The peptides and corresponding proteins that were commonly identified in two biological samples (total 4 replicates) were considered as confident protein identifications. All identified proteins were then searched using UniProtKB/Swiss-Prot Release 52.3, TMHMM 2.0, and PubMed, to obtain information about their subcellular localization. The presence of predicted or verified transmembrane domains, glycosylphosphatidylinositol (GPI)-anchors and the lipid consensus sequences for myristoylation, pamitolyation, geranylgeranylation, farnesylation, and prenylation was used to classify proteins as either a membrane protein, or a membrane-associated protein [31]. Identified proteins were also analyzed by UniProtKB for the predicted presence of these motifs in order to provide an additional criterion for the evaluation. The overall experimental results for lipid raft core proteome of neonatal mouse brain thus characterized are shown in Figure 3. The complete lists of identified proteins, categorized as plasma membrane

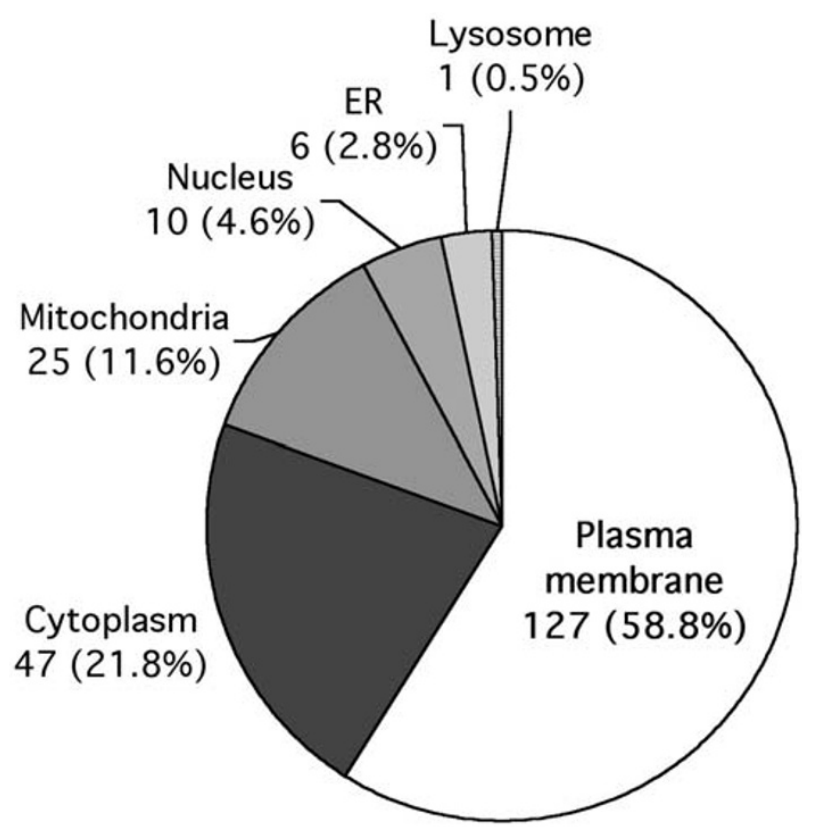

Figure 3

Cellular localization of identified proteins in lipid rafts from neonatal mouse brain. Cellular localization was annotated based on Gene Ontology (GO) terms and the PubMed literature database. The number of proteins and their percentage of the total identified proteins associated with each cellular location are indicated. 
(PM) or PM-associated proteins and non-PM proteins, are shown in Tables 1 and 2, respectively.

The identified core proteome in the lipid rafts of neonatal mouse brain covered a wide range of sizes (8.0 319.6 $\mathrm{kDa}$ ). Up to 216 non-redundant proteins were identified from $100 \mu \mathrm{l}$ of a lipid raft fraction by TubeGeLC-MS/MS, $75 \%$ of these proteins were identified by at least two peptide matches and 25\% of those identified were based upon a single peptide match. Although protein identifications based upon a single peptide match may be problematic, this does not necessarily imply a potential false identification [34]. For example, caveolin-1 (cav-1) was detected in raft samples from neonatal mouse brain by immunoblots, but was represented in each of the 4 replicates identified by mass spectrometry by a single peptide match. Using the Gene Ontology (GO) classifications and PubMed database searches, 127 (58.8\%) of the proteins identified were PM or PM-associated proteins, with 18 (14.2\%) having a GPI-anchoring site and 34 (26.8\%) with other lipid-anchoring sites as described above. Many of the PM proteins identified were reported previously as being lipid raft proteins by conventional biochemical procedures. Typical raft marker proteins, such as caveolin-1, flotillin-1 and -2, Fyn and Src, were identified in the lipid raft preparations from neonatal mouse brain. Functional categories revealed that the identified PM proteins cover a broad range of neural functions involving neurodevelopment. Several proteins are known to function as part of the neurotransmitter release and re-uptake machinery; 3 syntaxin (Stx) proteins, Stx1A, Stx1B, Stx7; synaptosomalassociated protein 25 (Snap25); synaptotagmin (Syt) proteins, Syt1 and Sty7; vesicle-associated membrane proteins (Vamp), Vamp1 and Vamp2; regulating synaptic membrane exocytosis protein 1 (RIM1); and the glutamate receptor (GluR1) were all present in the raft fractions. Relatively large numbers of guanine nucleotidebinding protein ( $G$ protein) isoforms and Ras subfamily of GTPases were identified; G(s) $\alpha, G(i) \alpha 1, G(i) \alpha 2, G(o) \alpha$, $\mathrm{G}(\mathrm{k}) \alpha 3, \mathrm{G}(\mathrm{olf}) \alpha, \mathrm{G}(\mathrm{q}) \alpha, \mathrm{G}(\mathrm{z}) \alpha, \mathrm{G} \alpha 11, \mathrm{G} \alpha 12, \mathrm{G}(\mathrm{I}) / \mathrm{G}(\mathrm{S}) /$ G(T) $\beta 1 ， \quad G(I) / G(S) / G(O) \gamma 2 ， G(I) / G(S) / G(O) \gamma 4 ， G(I) /$ $\mathrm{G}(\mathrm{S}) / \mathrm{G}(\mathrm{O}) \gamma 12$ and Rab1A, Rab1B, Rab2A, Rab3A, Rab5A, Rab5C, Rab10, Rab11B, Rab14, Rab15, Rab33B, Rab35, p21Rac1, p21Rac3, Rab GDI $\alpha$, RIN3, and G3BP. These proteins have been implicated in a variety of developmental processes in neonatal brain, including signal transduction, neurotransmitter release, and membrane trafficking [2]. Another important group of proteins in the neonatal brain-raft proteome comprises the cell adhesion/recognition molecules for cell-cell communication. Twenty-four such proteins were identified; contactin1 (Cntn1), Cntn2, Cntn4, and Cntn6, neurotrimin, Thy1, neurotractin (Kilon protein), Nap22, Gap43, paralemmin, desmocollin-2, neurexin-3 $\alpha$, Ncam2, Ncam180, dynactin, glypican (Gpc)1, Gpc 2, Gpc4, limbic system-associated mem- brane protein (LSAMP), transmembrane phosphoprotein Cbp, neurofibromin, opioid-binding cell adhesion molecule (Obcam), Alpha-3 catenin, and cadherin-13. These cell surface communication proteins are known to participate in the formation of neuronal networks in the brain during development, specifically axon growth, synapse formation, and fasciculation [35-38]. Several transporters and non-receptor type channel proteins were also identified; $\mathrm{Na}(+) / K(+)$ ATPase (ATP1A1, ATP1A2 and ATP1A3), small conductance calcium-activated potassium channel protein 3 (Kcnn3), plasma membrane calcium-transporting ATPase 1, Slc3a2, GDNF family receptor alpha-2, integrin-associated protein, integral membrane protein $2 \mathrm{~B}$, sensory neuron sodium channel, L-type calcium channel subunit delta, aquaporin-1, and chloride channel protein 6 (Clc-6). Calcium and phospholipid binding proteins cupine (Cnpe)2, Cnpe4, Cnpe591, annexin (Anx)2A, Anx4A, Anx5A, Anx6A, and Anx7A were also identified. A number of proteins of unknown function were also identified, such as receptor-type tyrosine-protein phosphatase gamma, protein C10orf58 homolog, Coxsackie's virus and adenovirus receptor homologs. As expected, since these raft proteins are from neonatal mouse brain, myelin proteins (present in adult brain tissue) such as myelin basic protein (MBP), myelin proteolipid protein (PLP), oligodendrocyte-myelin glycoprotein (Omg), and 2',3'-cyclic-nucleotide 3'-phosphodiesterase (CNPase), were not represented. Functional annotation and grouping of the major neonate-brain raft proteome will provide a basis for determining the potential targets of lipid raft disorganization in mouse models of neonatal brain disorders.

As reported in most raft proteomic studies $[8,10,11,14,19,39-43]$, non-PM proteins were also found in the raft samples in the present study (Fig. 2 and Table 2). Eighty-nine of the $216(41.2 \%)$ identified proteins from neonatal mouse brain rafts were predicted to be non-PM proteins by their GO terms. They are comprised of 47 cytoplasmic proteins including 20 cellular structural proteins (such as tubulins, actins, keratins, and microtubule-associated proteins), 25 mitochondrial proteins, 10 nuclear proteins, 6 ER proteins, and 1 lysosomal protein. Proteins from other subcellular compartments such as endosome and Golgi apparatus were poorly represented. The presence of subcellular membrane and cytoplasmic proteins in lipid raft fractions have been discussed in several proteomic studies $[1,8,11,43-46]$. One possibility is the contamination of non-plasma membrane proteins during gradient purification. The position of membrane particles in the density gradient ultracentrifugation is determined mainly by the ratio of its lipid and protein contents; different ratios of lipids to proteins for the various intracellular membrane particles could lead them to have different buoyant properties in density gradients. In 
Table I: Plasma membrane associated proteins identified in the lipid rafts of neonatal mouse brain

\begin{tabular}{|c|c|c|c|c|c|c|c|}
\hline Acc. No. & Protein name & Pep $^{a}$ & $\% \operatorname{cov}^{b}$ & MW (KDa) & PTMc & Spectral count ${ }^{d}$ & SDe \\
\hline$P 12960$ & Contactin-I (Neural cell surface protein F3) & 26 & 35.03 & 113.4 & GPI & 174.0 & 4.0 \\
\hline Q91XV3 & Neuronal axonal membrane protein NAP- 22 & 8 & 66.52 & 22.1 & $\begin{array}{l}\text { Lipid } \\
\text { anchor }\end{array}$ & 125.0 & 0.6 \\
\hline P59216 & G-protein $\mathrm{G}(\mathrm{o})$, alpha subunit I & 7 & 25.28 & 40.1 & $\begin{array}{l}\text { Lipid } \\
\text { anchor }\end{array}$ & 101.0 & 2.0 \\
\hline PI4824 & Annexin A6 & 21 & 41.43 & 75.8 & & 99.0 & 22.0 \\
\hline Q8BLK3 & Limbic system-associated membrane protein & 5 & 17.94 & 38.0 & GPI & 66.0 & 1.0 \\
\hline Q80Z24 & Neuronal growth regulator I (Neurotractin) & 4 & 14.99 & 37.9 & GPI & 56.5 & 2.5 \\
\hline Q61330 & Contactin-2 & 13 & 20.69 & 113.2 & GPI & 44.5 & 5.5 \\
\hline P3840I & G-protein G(i), alpha-I subunit & 5 & 19.03 & 40.4 & $\begin{array}{l}\text { Lipid } \\
\text { anchor }\end{array}$ & 42.5 & 10.5 \\
\hline 008917 & Flotillin-I & 8 & 29.04 & 47.5 & & 40.0 & 0.0 \\
\hline Q8BFZ9 & SPFH domain-containing protein 2 & 3 & 11.30 & 38.9 & & 38.0 & 1.2 \\
\hline Q9Z2S9 & Flotillin-2 (Reggie-1) (REG-I) & 6 & 22.22 & 41.7 & & 36.5 & 1.5 \\
\hline PI3595 & Neural cell adhesion molecule I, I80 kDa isoform & 6 & 9.43 & 119.4 & & 32.5 & 10.5 \\
\hline P38402 & G-protein G(i), alpha-2 subunit & 2 & 8.78 & 40.5 & $\begin{array}{l}\text { Lipid } \\
\text { anchor }\end{array}$ & 30.0 & 4.0 \\
\hline Q9ZIG4 & Vacuolar proton pump subunit I & 7 & 9.43 & 96.5 & & 28.5 & 0.5 \\
\hline Q62188 & Dihydropyrimidinase-related protein 3 (DRP-3) & 7 & 20.39 & 61.9 & & 21.5 & 0.5 \\
\hline P27600 & G-protein alpha- 12 subunit ( $\mathrm{G}$ alpha- 12 ) & 2 & 8.49 & 44.0 & $\begin{array}{l}\text { Lipid } \\
\text { anchor }\end{array}$ & 20.5 & 5.5 \\
\hline 070443 & G-protein $\mathrm{G}(\mathrm{z})$, alpha subunit $(\mathrm{G}(\mathrm{x})$ alpha chain) & 4 & 17.85 & 40.9 & & 19.5 & 1.5 \\
\hline Q99PJ0 & Neurotrimin & 3 & 11.95 & 38.0 & GPI & 17.0 & 1.0 \\
\hline $\begin{array}{l}\text { Q9WTR } \\
5\end{array}$ & Cadherin-13 & 4 & 9.26 & 78.3 & GPI & 17.0 & 2.0 \\
\hline P21278 & G-protein alpha-II subunit & 3 & 9.78 & 42.0 & & 15.0 & 0.6 \\
\hline P5II50 & Ras-related protein Rab-7 & 3 & 19.90 & 23.5 & $\begin{array}{l}\text { Lipid } \\
\text { anchor }\end{array}$ & 14.5 & 0.5 \\
\hline Q8VDN2 & Sodium/potassium-transporting ATPase alpha-I chain & 5 & 8.61 & 113.0 & & 13.5 & 0.5 \\
\hline P32736 & Opioid-binding protein/cell adhesion molecule & 3 & 13.08 & 38.1 & GPI & 13.0 & 2.0 \\
\hline P21279 & G-protein $G(q)$, alpha subunit & 3 & 13.64 & 41.5 & $\begin{array}{l}\text { Lipid } \\
\text { anchor }\end{array}$ & 13.0 & 0.0 \\
\hline P01831 & Thy-I membrane glycoprotein precursor (Thy-I) & 3 & 26.71 & 18.1 & GPI & 12.5 & 0.5 \\
\hline P59729 & Ras and Rab interactor 3 & 2 & 3.14 & 107.3 & & 12.0 & 2.0 \\
\hline Q6TMK6 & G-protein $\mathrm{G}(\mathrm{I}) / \mathrm{G}(\mathrm{S}) / \mathrm{G}(\mathrm{T})$ beta subunit & 2 & 8.81 & 37.4 & & 12.0 & 4.0 \\
\hline P06837 & Neuromodulin (Axonal membrane protein GAP-43 & 2 & 18.14 & 23.6 & $\begin{array}{l}\text { Lipid } \\
\text { anchor }\end{array}$ & 11.5 & 0.5 \\
\hline Q6PIE5 & Sodium/potassium-transporting ATPase alpha- 2 chain & 3 & 10.71 & 112.2 & & 11.0 & 1.0 \\
\hline P6282I & Ras-related protein Rab-IA & 2 & 16.26 & 22.7 & $\begin{array}{l}\text { Lipid } \\
\text { anchor }\end{array}$ & 11.0 & 1.0 \\
\hline P53994 & Ras-related protein Rab- $2 \mathrm{~A}$ & 3 & 20.38 & 23.5 & $\begin{array}{l}\text { Lipid } \\
\text { anchor }\end{array}$ & 10.5 & 0.5 \\
\hline P38403 & G-protein $G(k)$, alpha subunit & 3 & 13.64 & 40.6 & $\begin{array}{l}\text { Lipid } \\
\text { anchor }\end{array}$ & 10.0 & 2.0 \\
\hline Q8BKVI & Glypican-2 precursor & 2 & 5.88 & 63.3 & GPI & 10.0 & 2.0 \\
\hline Q68FD5 & Clathrin heavy chain & 5 & 4.06 & 191.6 & & 10.0 & 3.0 \\
\hline Q91X78 & SPFH domain-containing protein I & 6 & 24.48 & 38.9 & & 9.5 & 2.5 \\
\hline P39688 & Proto-oncogene tyrosine-protein kinase Fyn & 2 & 3.57 & 59.9 & $\begin{array}{l}\text { Lipid } \\
\text { anchor }\end{array}$ & 9.5 & 1.5 \\
\hline Q61735 & Integrin-associated protein (IAP) & 2 & 4.64 & 33.1 & & 9.5 & 0.5 \\
\hline P97792 & Coxsackievirus and adenovirus receptor homolog & 2 & 6.04 & 39.9 & $\begin{array}{l}\text { Lipid } \\
\text { anchor }\end{array}$ & 9.5 & 1.5 \\
\hline $\begin{array}{l}\text { Q9WUC } \\
3\end{array}$ & Lymphocyte antigen $\mathrm{Ly}-6 \mathrm{H}$ precursor & 2 & 12.32 & 14.67 & GPI & 9.5 & 1.5 \\
\hline Q6PIC6 & Sodium/potassium-transporting ATPase alpha- 3 chain & 3 & 4.45 & 111.7 & & 9.0 & 1.0 \\
\hline Q8BMT4 & Leucine-rich repeat-containing protein 33 & 2 & 2.75 & 77.1 & & 9.0 & 1.0 \\
\hline P48036 & Annexin A5 & 5 & 21.07 & 35.8 & & 9.0 & 1.0 \\
\hline PI7182 & Alpha-enolase & 3 & 11.57 & 47.1 & & 9.0 & 0.6 \\
\hline 008532 & L-type calcium channel subunit delta & 2 & 2.75 & 124.6 & & 8.5 & 2.5 \\
\hline P63044 & Vesicle-associated membrane protein 2 (VAMP-2) & 3 & 35.09 & 12.7 & & 8.0 & 0.0 \\
\hline P54227 & Stathmin (Phosphoprotein p19) & 2 & 14.97 & 17.3 & & 8.0 & 1.0 \\
\hline P61027 & Ras-related protein Rab-10 & 3 & 16.58 & 22.5 & $\begin{array}{l}\text { Lipid } \\
\text { anchor }\end{array}$ & 8.0 & 1.0 \\
\hline Q9QZF2 & Glypican-I precursor & 3 & 8.99 & 61.4 & GPI & 8.0 & 2.0 \\
\hline Q3UIF9 & Transmembrane phosphoprotein Cbp & 2 & 7.48 & 46.5 & $\begin{array}{l}\text { Lipid } \\
\text { anchor }\end{array}$ & 7.0 & 0.6 \\
\hline Q69Z26 & Contactin-4 & 3 & 2.15 & 117.5 & GPI & 7.0 & 1.0 \\
\hline Q9R0N7 & Synaptotagmin-7 (Synaptotagmin VII) (SytVII) & 2 & 7.71 & 45.5 & & 6.5 & 0.5 \\
\hline Q9Z0P4 & Paralemmin & 3 & 10.73 & 41.6 & $\begin{array}{l}\text { Lipid } \\
\text { anchor }\end{array}$ & 6.5 & 1.5 \\
\hline O35454 & Chloride channel protein 6 (ClC-6) & 4 & 6.56 & 97.0 & & 6.5 & 1.5 \\
\hline P51863 & Vacuolar ATP synthase subunit $d$ & 2 & 6.86 & 40.3 & & 6.0 & 0.6 \\
\hline
\end{tabular}


Table I: Plasma membrane associated proteins identified in the lipid rafts of neonatal mouse brain (Continued)

\begin{tabular}{|c|c|c|c|c|c|c|c|}
\hline P62814 & Vacuolar ATP synthase subunit $B$, brain isoform & 3 & 8.04 & 56.6 & & 6.0 & 1.0 \\
\hline Q9ER00 & Syntaxin-12 & 2 & 11.72 & 31.19 & & 6.0 & 2.0 \\
\hline Q7SIG6 & Development and differentiation-enhancing factor 2 & 2 & 2.84 & 106.8 & & 6.0 & 1.0 \\
\hline Q6PHN9 & Ras-related protein Rab-35 & 2 & 5.50 & 23.0 & $\begin{array}{l}\text { Lipid } \\
\text { anchor }\end{array}$ & 5.5 & 0.5 \\
\hline $\mathrm{P} 63213$ & G-protein $\mathrm{G}(\mathrm{I}) / \mathrm{G}(\mathrm{S}) / \mathrm{G}(\mathrm{O})$ gamma-2 subunit & 2 & 8.78 & 37.4 & & 5.5 & 0.5 \\
\hline PI4094 & Sodium/potassium-transporting ATPase beta-I chain & 2 & 8.25 & 35.2 & & 5.0 & 2.0 \\
\hline Q6PCX7 & Repulsive guidance molecule A & 2 & 6.62 & 50.0 & GPI & 5.0 & 2.0 \\
\hline P70296 & Phosphatidylethanolamine-binding protein (PEBP) & 3 & 28.65 & 20.7 & & 5.0 & 3.0 \\
\hline P59108 & Copine-2 (Copine II) & 3 & 6.76 & 61.0 & & 5.0 & 1.7 \\
\hline Q9WV55 & VAMP-associated protein A & 2 & 4.98 & 27.3 & & 4.5 & 0.5 \\
\hline P46096 & Synaptotagmin-I & 2 & 5.71 & 47.4 & $\begin{array}{l}\text { Lipid } \\
\text { anchor }\end{array}$ & 4.5 & 1.5 \\
\hline Q9DIGI & Ras-related protein Rab-IB & 2 & 16.50 & 22.2 & $\begin{array}{l}\text { Lipid } \\
\text { anchor }\end{array}$ & 4.5 & 0.5 \\
\hline P07356 & Annexin A2 (Annexin II) & 3 & 13.95 & 38.5 & & 4.5 & 1.5 \\
\hline Q99KR6 & RING finger protein 34 & 2 & 4.53 & 42.0 & & 4.0 & 1.0 \\
\hline Q9IV4I & Ras-related protein Rab-14 & 2 & 12.62 & 23.9 & $\begin{array}{l}\text { Lipid } \\
\text { anchor }\end{array}$ & 4.0 & 1.2 \\
\hline PI0852 & 4F2 cell-surface antigen heavy chain & 2 & 5.14 & 58.3 & & 4.0 & 0.6 \\
\hline P35279 & Ras-related protein Rab-6A (Rab-6) & 2 & 5.34 & 23.6 & $\begin{array}{l}\text { Lipid } \\
\text { anchor }\end{array}$ & 3.5 & 1.5 \\
\hline $\begin{array}{l}\text { Q9CQD } \\
\text { I }\end{array}$ & Ras-related protein Rab-5A & 2 & 10.28 & 23.6 & $\begin{array}{l}\text { Lipid } \\
\text { anchor }\end{array}$ & 3.5 & 0.5 \\
\hline O35963 & Ras-related protein Rab-33B & 2 & 4.82 & 25.8 & $\begin{array}{l}\text { Lipid } \\
\text { anchor }\end{array}$ & 3.5 & 0.5 \\
\hline Q8K386 & Ras-related protein Rab-15 & 2 & 5.21 & 24.3 & $\begin{array}{l}\text { Lipid } \\
\text { anchor }\end{array}$ & 3.5 & 1.5 \\
\hline P60764 & Ras-related $C 3$ botulinum toxin substrate 3 & 2 & 7.33 & 21.4 & $\begin{array}{l}\text { Lipid } \\
\text { anchor }\end{array}$ & 3.5 & 0.5 \\
\hline Q9QXL2 & Kinesin family member $2 \mathrm{IA}$ & 2 & 1.14 & 186.53 & & 3.5 & 0.5 \\
\hline Q8R4A8 & G-protein $\mathrm{G}(\mathrm{s})$, alpha subunit & 3 & 13.64 & 45.7 & $\begin{array}{l}\text { Lipid } \\
\text { anchor }\end{array}$ & 3.5 & 1.5 \\
\hline Q9JMB8 & Contactin-6 & 3 & 3.21 & 113.8 & GPI & 3.5 & 2.5 \\
\hline Q65CLI & Alpha-3 catenin (Alpha T-catenin) & 1 & 1.79 & 99.8 & & 3.5 & 1.5 \\
\hline Q60547 & Synaptonemal complex protein 3 & 3 & 6.01 & 27.1 & & 3.0 & 0.6 \\
\hline Q9DAS9 & G-protein $\mathrm{G}(\mathrm{I}) / \mathrm{G}(\mathrm{S}) / \mathrm{G}(\mathrm{O})$ gamma-12 subunit & 4 & 22.86 & 78.7 & $\begin{array}{l}\text { Lipid } \\
\text { anchor }\end{array}$ & 3.0 & 1.0 \\
\hline P97449 & Aminopeptidase $\mathrm{N}$ (Membrane protein pl6I) & I & 1.87 & 109.7 & & 3.0 & 1.0 \\
\hline Q9JHS3 & Late endosomal/lysosomal $\mathrm{Mpl}$-interacting protein & 2 & 14.52 & 13.48 & & 3.0 & 1.0 \\
\hline P31324 & Prkar2b & 1 & 4.11 & 46.04 & & 3.0 & 1.5 \\
\hline P6I264 & Syntaxin-IB2 (Syntaxin IB) & 2 & 8.01 & 33.3 & & 2.5 & 1.5 \\
\hline P35278 & Ras-related protein Rab-5C & 2 & 6.51 & 23.4 & $\begin{array}{l}\text { Lipid } \\
\text { anchor }\end{array}$ & 2.5 & 0.5 \\
\hline P630II & Ras-related protein Rab-3A & 2 & 8.68 & 25.0 & $\begin{array}{l}\text { Lipid } \\
\text { anchor }\end{array}$ & 2.5 & 0.5 \\
\hline P97855 & Ras-GTPase-activating protein binding protein I & $\mathrm{I}$ & 3.02 & 51.8 & & 2.5 & 0.5 \\
\hline Q9CYH2 & Protein CIOorf58 homolog & 2 & 5.99 & 24.4 & & 2.5 & 0.5 \\
\hline PII505 & Plasma membrane calcium-transporting ATPase I & 1 & 1.43 & 138.7 & & 2.5 & 0.5 \\
\hline P05480 & Neuronal proto-oncogene tyrosine-protein kinase Src & 2 & 5.38 & 60.6 & $\begin{array}{l}\text { Lipid } \\
\text { anchor }\end{array}$ & 2.5 & 0.5 \\
\hline Q07310 & Neurexin-3-alpha & 1 & 4.11 & 174.0 & & 2.5 & 0.5 \\
\hline 035136 & Neural cell adhesion molecule 2 & 1 & 1.56 & 93.2 & GPI & 2.5 & 1.5 \\
\hline O8905I & Integral membrane protein $2 B$ & 2 & 6.04 & 30.3 & & 2.5 & 0.5 \\
\hline 008842 & GDNF family receptor alpha-2 & I & 3.68 & 51.6 & GPI & 2.5 & 0.5 \\
\hline 008545 & Ephrin-A3 precursor & 2 & 8.60 & 21.2 & GPI & 2.5 & 0.5 \\
\hline Q9RIT7 & Inducible T-cell co-stimulator (CD278 antigen) & 2 & 8.54 & 225.30 & & 2.5 & 0.5 \\
\hline P60879 & Synaptosomal-associated protein 25 & 2 & 6.83 & 23.3 & $\begin{array}{l}\text { Lipid } \\
\text { anchor }\end{array}$ & 2.0 & 1.0 \\
\hline P80236 & Ras-related $\mathrm{C} 3$ botulinum toxin substrate $\mathrm{I}$ & 3 & 18.42 & 8.8 & & 2.0 & 1.0 \\
\hline P68404 & Protein kinase $C$ beta type & $\mathrm{I}$ & 2.38 & 76.9 & & 2.0 & 0.6 \\
\hline Q04690 & Neurofibromin & 2 & 3.81 & 319.6 & & 2.0 & 0.6 \\
\hline Q60437 & Insulin receptor substrate $\mathrm{p} 53$ & 2 & 6.15 & 57.64 & & 2.0 & 0.6 \\
\hline Q614II & GTPase HRas & 2 & 12.77 & 21.3 & $\begin{array}{l}\text { Lipid } \\
\text { anchor }\end{array}$ & 2.0 & 0.6 \\
\hline P5I655 & Glypican-4 precursor (K-glypican) & 2 & 4.86 & 62.6 & GPI & 2.0 & 1.0 \\
\hline P23818 & Glutamate receptor I (GluR-I) & 1 & 2.21 & 101.57 & & 2.0 & 0.6 \\
\hline Q8VBX4 & C-type lectin domain family 4 member $\mathrm{K}$ & 1 & 4.24 & 37.6 & & 2.0 & 0.6 \\
\hline Q8JZW4 & Copine-5 (Copine V) & $\mathrm{I}$ & 2.53 & 65.6 & & 2.0 & 1.0 \\
\hline Q8BLR2 & Copine-4 (Copine IV) & $\mathrm{I}$ & 2.70 & 62.4 & & 2.0 & 0.6 \\
\hline Q02013 & Aquaporin-I & 1 & 7.49 & 28.66 & & 2.0 & 1.2 \\
\hline Q07076 & Annexin A7 & 1 & 3.46 & 49.9 & & 2.0 & 1.7 \\
\hline P97429 & Annexin A4 (Annexin IV) & 3 & 10.09 & 35.9 & & 2.0 & 0.6 \\
\hline Q9DBE8 & Alpha-I,3-mannosyltransferase ALG2 & 1 & 3.86 & 47.4 & & 2.0 & 1.0 \\
\hline P84078 & ADP-ribosylation factor I & 2 & 6.15 & 20.6 & & 2.0 & 1.0 \\
\hline
\end{tabular}


Table I: Plasma membrane associated proteins identified in the lipid rafts of neonatal mouse brain (Continued)

\begin{tabular}{|c|c|c|c|c|c|c|c|}
\hline Q6QIY3 & Sensory neuron sodium channel & $T$ & 3.09 & 220.6 & & 2.0 & 0.6 \\
\hline P49817 & Caveolin-I & 1 & 7.91 & 20.54 & & 2.0 & 0.6 \\
\hline PI8708 & Vesicle-fusing ATPase & 2 & 2.69 & 82.54 & & 1.5 & 0.5 \\
\hline 070439 & Syntaxin-7 & 2 & 5.41 & 29.8 & & 1.5 & 0.5 \\
\hline PI6546 & Spectrin alpha chain, brain & 1 & 1.24 & 274.7 & & 1.5 & 0.5 \\
\hline Q9QZB0 & Regulator of G-protein signaling 17 & 1 & 6.22 & 24.3 & & 1.5 & 0.5 \\
\hline Q9JIR4 & Regulating synaptic membrane exocytosis protein I & 2 & 6.07 & 179.7 & & 1.5 & 0.5 \\
\hline Q05909 & Receptor-type tyrosine-protein phosphatase gamma & 2 & 9.72 & 161.2 & & 1.5 & 0.5 \\
\hline P46638 & Ras-related protein Rab-I IB & 2 & 9.72 & 24.5 & $\begin{array}{l}\text { Lipid } \\
\text { anchor }\end{array}$ & 1.5 & 0.5 \\
\hline P05696 & Protein kinase $\mathrm{C}$ alpha type(PKC-alpha) & I & 2.09 & 76.8 & & 1.5 & 0.5 \\
\hline O35764 & Neuronal pentraxin receptor & $\mathrm{I}$ & 2.84 & 52.37 & & 1.5 & 0.5 \\
\hline $\begin{array}{l}\text { Q8CGK } \\
7\end{array}$ & G-protein G(olf), alpha subunit & 6 & 20.74 & 44.3 & & 1.5 & 0.5 \\
\hline P50I53 & G-protein $G(I) / G(S) / G(O)$ gamma-4 subunit & 2 & 9.35 & 84.1 & $\begin{array}{l}\text { Lipid } \\
\text { anchor }\end{array}$ & 1.5 & 0.5 \\
\hline Q99KJ8 & Dynactin subunit 2 & I & 4.75 & 44.0 & & 1.5 & 0.5 \\
\hline
\end{tabular}

aPep: peptide counts; $b \%$ cov: protein coverage\%; c PTM: posttranslational lipid modification, GPI and lipid anchor: myristoylation, pamitolyation, geranylgeranylation, farnesylation, and prenylation; ${ }^{d}$ Spectral count: total MS/MS spectral counts. Number represents mean value of 4 replicates; ${ }^{c}$ standard deviation of spectral counts in 4 replicates.

Table 2: Non-PM proteins identified in the lipid rafts of neonatal mouse brain

\begin{tabular}{|c|c|c|c|c|c|c|c|}
\hline Acc. No. & Protein name & Pep $^{a}$ & $\%$ Cov $^{b}$ & MW (KDa) & Loc. ${ }^{c}$ & Spectral count ${ }^{d}$ & SDe \\
\hline P69893 & Tubulin beta-I chain & 12 & 38.60 & 49.67 & cyto & 262.0 & 14.0 \\
\hline P6836। & Tubulin alpha-I chain & 9 & 30.44 & 50.15 & cyto & 175.0 & 20.0 \\
\hline Q7IFK5 & Actin, cytoplasmic I (Beta-actin) & 5 & 21.39 & 41.74 & cyto & 102.5 & 4.5 \\
\hline Q03265 & ATP synthase alpha chain & 10 & 26.63 & 59.75 & $\mathrm{mc}$ & 63.0 & 4.0 \\
\hline P56480 & ATP synthase beta chain & 9 & 20.83 & 56.30 & $\mathrm{mc}$ & 51.5 & 5.5 \\
\hline P04I04 & Keratin, type II cytoskeletal I & 3 & 5.59 & 65.1 & cyto & 37.0 & 4.0 \\
\hline P62629 & Elongation factor I-alpha I & 3 & 9.33 & 50.11 & cyto & 36.0 & 5.0 \\
\hline PI9378 & Heat shock cognate 7l kDa protein & 4 & 10.39 & 70.8 & cyto & 33.0 & 1.0 \\
\hline Q922U2 & Keratin, type II cytoskeletal 5 & 2 & 4.15 & 61.8 & cyto & 26.5 & 6.5 \\
\hline $\mathrm{PI} 4873$ & Microtubule-associated protein IB (MAP IB) & 7 & 4.34 & 270.41 & cyto & 25.5 & 3.5 \\
\hline Q6IFZ6 & Keratin, type II cytoskeletal Ib & 2 & 4.20 & 61.4 & cyto & 25.5 & 3.5 \\
\hline P97427 & Dihydropyrimidinase-related protein I & 4 & 8.93 & 62.17 & cyto & 25.0 & 0.0 \\
\hline Q62188 & Dihydropyrimidinase-related protein 3 & 7 & 20.39 & 61.94 & cyto & 21.5 & 0.5 \\
\hline PI4733 & Lamin-BI & 5 & 12.80 & 66.66 & nuc & 19.0 & 3.0 \\
\hline P68372 & Tubulin beta- $2 \mathrm{C}$ chain & 2 & 6.76 & 49.83 & cyto & 18.5 & 1.5 \\
\hline Q6IG00 & Keratin, type II cytoskeletal 4 & 2 & 1.68 & 57.7 & cyto & 18.0 & 1.0 \\
\hline Q60932 & Voltage-dependent anion-selective channel protein I & 7 & 38.31 & 32.35 & $\mathrm{mc}$ & 16.5 & 3.5 \\
\hline P48962 & ADP/ATP translocase I & 3 & 11.15 & 32.77 & $\mathrm{mc}$ & 15.0 & 2.0 \\
\hline Q922F4 & Tubulin beta- 6 chain & 2 & 3.81 & 50.09 & cyto & 14.5 & 0.5 \\
\hline Q04447 & Creatine kinase B-type & 3 & 12.63 & 42.71 & cyto & 13.5 & 2.5 \\
\hline P67778 & Prohibitin & 4 & 21.03 & 29.82 & $\mathrm{mc}$ & 12.5 & 1.5 \\
\hline Q10758 & Keratin, type II cytoskeletal 8 & 2 & 3.33 & 53.9 & cyto & 12.5 & 0.5 \\
\hline Q61696 & Heat shock $70 \mathrm{kDa}$ protein IA & 2 & 5.78 & 70.08 & cyto & 12.0 & 1.0 \\
\hline 008553 & Dihydropyrimidinase-related protein 2 & 5 & 13.84 & 62.17 & cyto & 11.5 & 2.5 \\
\hline P46633 & Heat shock protein HSP 90-alpha (HSP 86) & 2 & 3.56 & 84.72 & cyto & 10.5 & 2.5 \\
\hline P6310I & 14-3-3 protein zeta/delta & 2 & 12.30 & 27.77 & cyto & 10.5 & 0.5 \\
\hline Q60930 & Voltage-dependent anion-selective channel protein 2 & 3 & 14.29 & 31.73 & $\mathrm{mc}$ & 10.0 & 0.0 \\
\hline Q9ERD7 & Tubulin beta- 3 chain & 2 & 9.35 & 50.42 & cyto & 10.0 & 1.0 \\
\hline P50672 & Cytochrome c oxidase subunit 2 & 2 & 11.50 & 25.82 & $\mathrm{mc}$ & 9.0 & 0.0 \\
\hline Q9DCT2 & $\mathrm{NADH}$-ubiquinone oxidoreductase $30 \mathrm{kDa}$ subunit & 2 & 6.35 & 34.00 & $\mathrm{mc}$ & 8.5 & 0.5 \\
\hline PI8760 & Cofilin-I (Cofilin, non-muscle isoform) & 2 & 15.24 & 18.43 & nuc & 8.5 & 1.5 \\
\hline P07823 & $78 \mathrm{kDa}$ glucose-regulated protein & 5 & 11.18 & 72.38 & er & 8.5 & 1.5 \\
\hline PII497 & Acetyl-CoA carboxylase I & I & 4.24 & 37.62 & cyto & 8.0 & 1.0 \\
\hline Q60931 & Voltage-dependent anion-selective channel protein 3 & 3 & 13.83 & 30.75 & $\mathrm{mc}$ & 7.5 & 0.5 \\
\hline P09445 & Elongation factor 2 & 2 & 2.92 & 95.27 & cyto & 7.5 & 0.5 \\
\hline P62977 & Ubiquitin & I & 21.33 & 8.57 & cyto & 7.0 & 1.0 \\
\hline
\end{tabular}


Table 2: Non-PM proteins identified in the lipid rafts of neonatal mouse brain (Continued)

\begin{tabular}{|c|c|c|c|c|c|c|c|}
\hline PI9783 & Cytochrome c oxidase subunit IV isoform I & 1 & 7.14 & 19.53 & $\mathrm{mc}$ & 7.0 & 2.0 \\
\hline $\mathrm{P} 14152$ & Malate dehydrogenase & I & 3.61 & 36.35 & $\mathrm{mc}$ & 6.5 & 0.5 \\
\hline PII499 & Heat shock protein HSP 90-beta & 2 & 3.88 & 83.20 & cyto & 6.5 & 0.5 \\
\hline PI 2787 & Cytochrome $\mathrm{c}$ oxidase polypeptide $\mathrm{Va}$ & I & 10.42 & 16.03 & $\mathrm{mc}$ & 6.5 & 0.5 \\
\hline P31253 & Ubiquitin-activating enzyme $\mathrm{EI} X$ & 2 & 7.35 & 50.99 & cyto & 6.0 & 3.0 \\
\hline P35564 & Calnexin & 2 & 4.92 & 67.28 & er & 6.0 & 1.0 \\
\hline Q9IVD9 & NADH-ubiquinone oxidoreductase $75 \mathrm{kDa}$ subunit & 2 & 3.99 & 79.75 & $\mathrm{mc}$ & 5.5 & 2.5 \\
\hline P56135 & ATP synthase $f$ chain, mitochondrial & 2 & 26.74 & 10.21 & $\mathrm{mc}$ & 5.5 & 1.5 \\
\hline P5।88I & ADP/ATP translocase 2 & 2 & 8.11 & 32.80 & $\mathrm{mc}$ & 5.5 & 0.5 \\
\hline Q8R429 & $\mathrm{SR} \mathrm{Ca}(2+)-A T P a s e ~ I$ & 2 & 3.12 & 109.43 & er & 5.0 & 1.0 \\
\hline Q9DB20 & ATP synthase $O$ subunit & 2 & 9.91 & 23.36 & $\mathrm{mc}$ & 5.0 & 1.0 \\
\hline Q8R429 & Calcium pump I (SERCAI) & 2 & 3.12 & 109.43 & er & 5.0 & 1.0 \\
\hline Q9IV6I & Sideroflexin-3 & I & 4.06 & 35.41 & $\mathrm{mc}$ & 4.5 & 0.5 \\
\hline P03995 & Glial fibrillary acidic protein, astrocyte (GFAP) & I & 2.56 & 49.92 & cyto & 4.5 & 1.5 \\
\hline Q9CQV8 & 14-3-3 protein beta/alpha & I & 5.43 & 21.22 & cyto & 4.5 & 2.5 \\
\hline P68368 & Tubulin alpha-4 chain & 2 & 3.11 & 50.14 & cyto & 3.5 & 0.5 \\
\hline P62962 & Profilin-I (Profilin I) & 2 & 21.74 & 14.83 & cyto & 3.5 & 0.5 \\
\hline Q8QZTI & Acetyl-CoA acetyltransferase & 2 & 7.09 & 44.82 & $\mathrm{mc}$ & 3.5 & 0.5 \\
\hline P62962 & Profilin-I & 2 & 21.74 & 14.82 & cyto & 3.5 & 0.5 \\
\hline Q02053 & Ubiquitin-activating enzyme EI I & 3 & 4.82 & 117.81 & cyto & 3.0 & 1.0 \\
\hline P42932 & T-complex protein I subunit theta & 3 & 6.59 & 59.43 & cyto & 3.0 & 2.0 \\
\hline 035129 & Prohibitin-2 & 4 & 21.03 & 29.82 & $\mathrm{mc}$ & 3.0 & 1.0 \\
\hline P31324 & Prkar2b & 1 & 4.11 & 46.04 & cyto & 3.0 & 0.0 \\
\hline P20357 & Microtubule-associated protein 2 (MAP 2) & 2 & 1.20 & 198.98 & cyto & 3.0 & 0.0 \\
\hline P34926 & Microtubule-associated protein IA (MAP IA) & 2 & 2.36 & 299.53 & cyto & 3.0 & 0.0 \\
\hline P52480 & Pyruvate kinase isozyme $\mathrm{M} 2$ & 4 & 12.48 & 57.76 & $\mathrm{mc}$ & 3.0 & 2.0 \\
\hline P63209 & S-phase kinase-associated protein IA & I & 9.32 & 18.53 & cyto & 3.0 & 1.0 \\
\hline P60879 & Synaptonemal complex protein 3 & 3 & 6.01 & 27.1 & nuc & 3.0 & 1.0 \\
\hline 088809 & Neuronal migration protein doublecortin & I & 3.56 & 40.61 & cyto & 2.5 & 0.5 \\
\hline PI7I56 & Heat shock-related $70 \mathrm{kDa}$ protein 2 & 2 & 3.01 & 69.74 & cyto & 2.5 & 1.5 \\
\hline Q9EQF6 & Dihydropyrimidinase-related protein 5 & I & 3.20 & 61.52 & cyto & 2.5 & 0.5 \\
\hline Q8BH59 & Calcium-binding mitochondrial carrier protein Aralar I & 2 & 4.59 & 74.57 & $\mathrm{mc}$ & 2.5 & 0.5 \\
\hline P48670 & Vimentin & 1 & 4.25 & 51.85 & cyto & 2.5 & 1.5 \\
\hline P803।5 & T-complex protein I subunit delta & 1 & 2.98 & 57.94 & cyto & 2.0 & 0.0 \\
\hline PII 984 & T-complex protein I subunit alpha $\mathrm{A}$ & I & 4.14 & 60.34 & cyto & 2.0 & 0.0 \\
\hline Q9JKK8 & Serine-protein kinase ATR & 1 & 2.36 & 84.26 & nuc & 2.0 & 0.0 \\
\hline Q04899 & Serine/threonine-protein kinase PCTAIRE-3 & I & 3.78 & 51.85 & nuc & 2.0 & 1.0 \\
\hline Q99PTI & Rho GDP-dissociation inhibitor I (Rho GDI I) & I & 7.88 & 23.41 & er & 2.0 & 0.0 \\
\hline Q61879 & Myosin-10 & 1 & 3.09 & 49.59 & cyto & 2.0 & 0.0 \\
\hline P24638 & Lysosomal acid phosphatase & 1 & 2.13 & 48.51 & $\begin{array}{l}\text { lysos } \\
\text { ome }\end{array}$ & 2.0 & 1.0 \\
\hline O7025I & Elongation factor I-beta & 2 & 12.56 & 24.56 & cyto & 2.0 & 0.0 \\
\hline Q9CPQ8 & ATP synthase g chain, mitochondrial & 1 & 18.63 & 11.43 & $\mathrm{mc}$ & 2.0 & 0.0 \\
\hline O35627 & Orphan nuclear receptor NRII3 & I & 2.52 & 40.89 & nuc & 2.0 & 1.0 \\
\hline P53026 & $60 \mathrm{~S}$ ribosomal protein $\mathrm{LIOa}$ & I & 6.98 & 24.78 & nuc & 2.0 & 1.0 \\
\hline P97524 & Very-long-chain acyl-CoA synthetase & 1 & 2.58 & 70.69 & er & 1.5 & 0.5 \\
\hline Q01853 & Transitional endoplasmic reticulum ATPase & 2 & 3.11 & 89.18 & cyto & 1.5 & 0.5 \\
\hline Q99JRI & Sideroflexin-I & I & 5.63 & 35.52 & $\mathrm{mc}$ & 1.5 & 0.5 \\
\hline Q62627 & PRKC apoptosis WTI regulator protein & 1 & 4.53 & 35.87 & nuc & 1.5 & 0.5 \\
\hline Q9DCS9 & $\mathrm{NADH}$-ubiquinone oxidoreductase PDSW subunit & I & 10.92 & 20.89 & $\mathrm{mc}$ & 1.5 & 0.5 \\
\hline P08249 & Malate dehydrogenase & 2 & 9.79 & 35.60 & $\mathrm{mc}$ & 1.5 & 0.5 \\
\hline Q8BGU5 & Cyclin fold protein I & I & 5.00 & 39.39 & nuc & 1.5 & 0.5 \\
\hline Q8CEE6 & PAS-kinase (PASKIN) & I & 1.16 & 151.27 & cyto & 1.5 & 0.5 \\
\hline P35980 & $60 S$ ribosomal protein $\mathrm{LI} 8$ & I & 6.99 & 21.5 & nuc & 1.5 & 0.5 \\
\hline
\end{tabular}

aPep: peptide counts; $b \%$ cov: protein coverage\%; ‘ Loc.: subcellular localization. mc. mitochondria, cyto. cytoplasm, er. endoplasmic reticulum; eSpectral count: total MS/MS spectral counts. Number represents mean value of 4 replicates; ${ }^{c}$ standard deviation of spectral counts in 4 replicates.

this context, any method used for preparing cell membrane 'lipid rafts' is likely to generate a fraction containing membranes from a number of sub-cellular membranes, but not necessarily one enriched specifically in plasma membrane lipid rafts [8]. Certain subcellular proteins highly enriched in raft samples may be structurally involved and play critical roles in cell membrane lipid raft organization. For example, the cellular structural proteins 
such as tubulins, actins, keratins, and microtubular proteins, are highly enriched in lipid raft samples including brain-rafts as shown in this study and many other reports $[7,8,13,28]$. These cytoskeletal proteins not only contribute to the structural organization of cytoplasm but also play important roles in regulating the topography of the plasma membrane and trafficking and in modulating the localization of lipid raft proteins in eukaryotic cells $[47,48]$. Additionally, many proteins could have multiple cellular localizations regulated by multiple mechanisms. For example, cytoplasmic microtubule-associated proteins and 14-3-3 proteins, histones, and mitochondrial ATP synthases and voltage-dependent anion-selective channel 1 (VDAC1), have also been identified in cell plasma membranes [44,49-52]. Thus, enrichment of certain non-PM proteins in lipid rafts (DRMs) may represent a true observation of protein localization in different biological conditions and not necessarily be due to cross-contamination acquired during purification.

\section{Compilation of proteins into abundance lists}

All proteins identified as PM protein or non-PM proteins in lipid rafts of neonatal mouse brain by TubeGeLC/MS/ MS are compiled in Tables 1 and 2, respectively, and were sorted by their relative abundance calculated from the MS/MS spectral counts. Mass spectrometry of proteins and peptides is not quantitative, therefore, it is difficult to assess the abundance of a particular protein from the MS data per se. However, recent studies with label-free LC-MS/ MS shotgun proteomics [29,53-57] revealed a relationship between protein abundance and sampling statistics, such as sequence coverage, peptide count, and spectral count. The use of sampling statistics is a promising method for measuring the relative protein abundance and detecting differentially expressed proteins. In general, the greater the amount of protein, the greater the MS signal intensity, number of spectral counts, sequenced peptides/ sequence coverage, total ion current (TIC), and total Xcorr or scores that combine these values. Label-free proteomics has emerged as an alternative to stable isotope labeling for protein quantitation. The MS/MS spectral count, which compares the number of MS/MS spectra assigned to each protein, was selected for relative protein abundance in this study. Although this method has a tendency to overestimate the abundance of large proteins because they yield more peptides and therefore more spectral counts than the smaller proteins, the results indicate that this may not be a fundamental problem [29]. In the current study, contactin-1 (113.4 kDa) had a MS/MS spectral count of 174, but the sodium/potassium-transporting ATPase alpha-3 chain, a protein of almost identical size $(111.7 \mathrm{kDa})$, had a spectral count of 9 (Table 1$)$. It is reasonable to assume that the former protein is much more abundant than the latter. When plotting MS/MS spectral count versus protein size for all proteins identified (data not shown), both the maximum spectral count distribution was highest for proteins with a size distribution of 20 50 kDa. Therefore, the bias that may be potentially caused by size towards larger proteins may not be overly large, when using MS/MS spectral counts as a measure of abundance [29]. About 50\% of proteins were identified with fewer than 5 total spectral counts, presumably due to their relatively low abundances. A total of 11 identified proteins with $>40$ spectral counts were arbitrarily categorized as the most abundant proteins in the lipid rafts from neonatal mouse brain. These include contactin-1, NAP22, G $\alpha(\mathrm{o})$, annexin-A6, Lsamp, neurotractin, contactin-2, $\mathrm{G} \alpha(\mathrm{i})$, and flotillin-1, as well as intracellular structural and mitochondrial proteins such as tubulins, actins, and ATP synthases. Proteins with total spectral counts from 5 to 40 were arbitrarily categorized as medium abundance proteins. The relative abundances agree well with published data $[7,18,19,30,39,40,42,43,45,49,58-71]$ and support our contention that the TubeGeLC-MS/MS approach provides a fair representation of the protein composition of the lipid rafts from neonatal mouse brain. The spectral count data for each identified protein provides proteome-wide semi-quantitative information on the relative abundance of lipid raft proteins.

\section{Comparison of protein identifications between GeLC-MSI MS and TubeGeLC-MSIMS}

In-gel digestion can be efficiently employed after protein mixtures are resolved by SDS-PAGE or directly polymerized into a 'tube-gel' without electrophoresis $[7,15]$. Both of these in gel-based protein digestion protocols give clean LC-MS/MS baselines as interfering substances, such as detergents, salts and lipids, can be effectively removed during washing steps. To compare the GeLC-MS/MS versus the TubeGeLC-MS/MS, four separate experiments were conducted using $100 \mu \mathrm{l}$ of sucrose-gradient isolated rafts that were subjected to a 1D SDS-PAGE combined with nanospray LC-MS/MS spectrometry (GeLC-MS/MS) modified by an established protocol [72], as described in Methods. The results for the peptides and corresponding proteins that were identified in a minimum of 2 of 4 independent experiments were used for comparative analyses. The comparison showed that about 200 proteins could also be identified by GeLC-MS/MS approach, with similar protein identifications, especially for high and medium abundance proteins, as compared to TubeGeLC-MS/MS (data not shown). However, the reproducibility of protein identified by GeLC-MS/MS was less than TubeGeLC-MS/ MS (see below).

\section{Reproducibility of raft proteome characterization by TubeGeLC-MSIMS}

To test the reproducibility of proteins identified, $3 \mathrm{raft}$ samples from 3 separate neonatal brains prepared by identical methods at the same time were processed by 
both TubeGeLC-MS/MS and GeLC-MS/MS protocols, and the resulting protein identifications for within technique variations compared. There was a $68.8 \pm 6.5 \%$ (SD) concordance in the proteins identified by TubeGeLC-MS/MS protocol among the $3 \mathrm{raft}$ samples. As expected, the high abundance proteins showed a higher reproducibility of identification. The non-concordant proteins of 30\% may reflect some false identification because $55 \%$ of the nonconcordant proteins had single or two peptide identifications. In addition, lipid raft isolations per se have a degree of variability. The results from the GeLC-MS/MS protocol yielded $45 \pm 11 \%$ of concordance for within technique protein identifications.

A MS/MS spectral-count method was employed as a semiquantitative measure for comparing proteins in different samples. Variability in protein abundance, calculated as MS/MS spectral counts, between the brain raft samples from two separate animals was evaluated and compared between the two approaches. The ratio of the spectral count per protein between these two samples was presented as fold-change and plotted against the average of the spectral count of the two samples. With the TubeGeLC-MS/MS method the fold-change was less than 2 for $\sim 80 \%$ of the identified proteins; the higher the abundance, the lower of fold changes as shown in Figure 4A. However, greater variations for low abundance proteins were evident, indicating that the sensitivity of quantifying changes for low abundance proteins was generally lower. The fold-change results of the same samples analyzed by the GeLC/MS/MS protocol are shown in Figure 4B; greater variations were evident for both high and low abundant proteins. These results suggested that there was larger experimental variation associated with $1 \mathrm{D}$ gel protein separation and extraction from the gel slices prior protein digestion and mass spectrometry using the GeLC/MS/MS method. One of the explanations is that lipid associated proteins and other hydrophobic proteins may not fully enter the gel lanes in the GeLC/MS/MS protocol, causing variations in quantitative analyses. Employing the TubeGeLC-MS/MS approach, despite the experimental variation in isolating the lipid rafts, the protein composition from replicate samples was less variable, indicating that this simple change in sample handling results in more reproducible results.

\section{Conclusion}

We have successfully combined a 'tube-gel' protein digestion protocol with nanospray LC-MS/MS analysis to carry out a high throughput proteomic mapping of lipid raft proteins isolated from neonatal mouse brain. Characterization of analytically difficult lipid raft proteins was simplified by this method. The MS/MS spectral count information from mass spectrometric analyses allowed for the label-free quantitation of relative protein abun- dances of more than 200 raft proteins from a single sample. The major advantage of this protocol is that the raft proteins are directly digested in a gel matrix without fractionation and purification, thus dramatically minimizing variation in protein yields due to losses during sample manipulation prior to mass spectrometry. With careful isolation of rafts, this protocol should allow for a reproducible quantitation of relative protein abundance in lipid rafts. This methodology should allow the investigation of the role of these specialized membranes under various biological conditions.

\section{Methods}

\section{Reagents and antibodies}

Sources for antibodies were as follows: caveolin-1 (Cav1), contactin-1 (Cntn-1), annexin-VI (Anx VI, Anx6A), GTP-binding protein $\alpha q(\mathrm{G} \alpha q)$, NAP-22, calnexin, $\alpha$ tubulin from Santa Cruz Biotechnology, CA USA; flotillin1 (flot-1): BD Transduction Laboratories, CA USA; mouse monoclonal antibody against $\beta$-COP: Sigma-Aldrich, $\mathrm{MO}$ USA; and mouse anti-human transferrin receptor antibody: Zymed Laboratories, CA USA. Trypsin Gold (MS grade) was obtained from Promega, WI, USA. All other reagents were from ThermoFisher Scientific, MA, USA.

\section{Preparation of raft-enriched detergent-resistant membranes from neonatal mouse brain}

All animal experiments were performed with the approval of the Institutional Animal Care and Research Advisory Committee at the Clement Zablocki Veterans Medical Center. Neonatal mice (postnatal day 1, C57Bl/6J, Jackson Laboratories) were sacrificed by decapitation. Details of protocols used to prepare the raft-enriched detergentresistant membranes have been described previously $[30,73]$. Briefly, frozen brains from neonatal mice, 50 60 $\mathrm{mg}$ of wet brain tissue, were homogenized in an ice-cold lysis buffer containing $5 \%$ glycerol in buffer A $(50 \mathrm{mM}$ Tris-HCl, $\mathrm{pH} 8.0,10 \mathrm{mM} \mathrm{MgCl}, 0.15 \mathrm{M} \mathrm{NaCl}, 20 \mathrm{mM}$ $\mathrm{NaF}, 1 \mathrm{mM} \mathrm{Na} \mathrm{VO}_{4}, 5 \mathrm{mM} \beta$-mercaptoethanol, $10 \mu \mathrm{g} / \mathrm{ml}$ aprotinin, $10 \mu \mathrm{g} / \mathrm{ml}$ leupeptin, $1 \mathrm{mM}$ PMSF), using a tissue homogenizer (PRO Scientific Inc., Oxford, CT USA) by three pulses of 10 seconds each, followed by 20 strokes of a Dounce homogenizer, pestle A. Tissue debris and nuclei were removed by centrifugation at $1,000 \mathrm{~g}$ for 5 minutes and the pellet was re-extracted. The protein concentration of the post-nuclear homogenates $(\mathrm{PNH})$ was measured using Protein Reagent (Bio-Rad, CA USA), adjusted to $2 \mathrm{mg} / \mathrm{ml}$ and $2 \mathrm{ml}$ of the homogenates extracted with $1 \%$ Triton X-100 (TX) on ice for $30 \mathrm{~min}$. The samples were mixed with an equal volume of ice-cold $80 \%(\mathrm{w} / \mathrm{v})$ sucrose in buffer $\mathrm{A}$, and then overlaid with 2.0 $\mathrm{ml}$ each of $35,30,25$, and $5 \%(\mathrm{w} / \mathrm{v})$ sucrose (all in buffer A). The sucrose gradient was centrifuged at $36,000 \mathrm{rpm}$ in a Sorval 90 ultracentrifuge using a TH-641 rotor for $15 \mathrm{hr}$ at $4{ }^{\circ} \mathrm{C}$. After ultracentrifugation, TX-resistant lipid rafts 

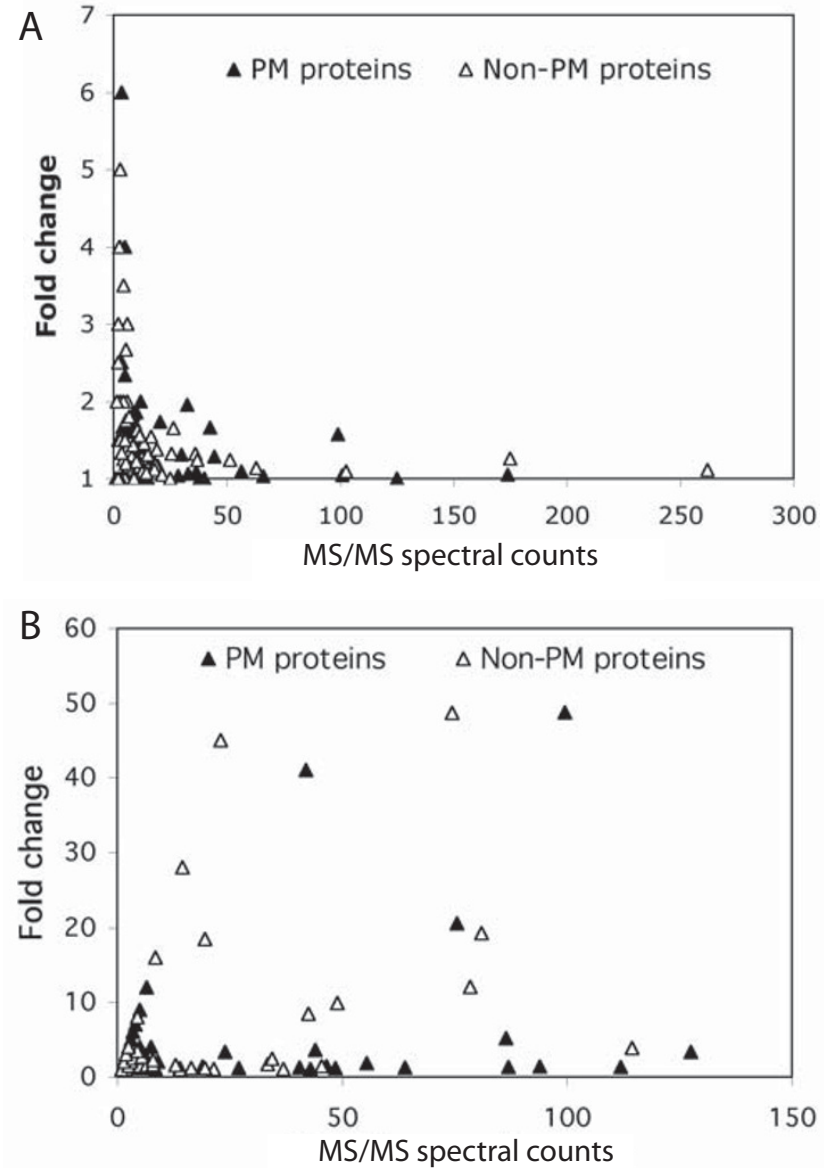

\section{Figure 4}

Variations of quantification by spectral counting. The variations in spectral counts for each protein were compared between the TubeGeLC/MS/MS and the GeLC/MS/MS protocols. The ratio of the spectral count per protein between two samples is presented as fold-change and plotted against the average of the spectral count of two samples. Panel A shows the results from the TubeGeLC/MS/MS method and panel B from the GeLC/MS/MS protocol.

appeared as an insoluble white light-scattering band at the interface between the 5\% and 25\% sucrose layer. Twelve $1.0 \mathrm{ml}$ fractions were collected from the top to bottom, with fractions 2-4 containing the rafts (density range of $1.055 \sim 1.115 \mathrm{~g} / \mathrm{ml}$ ). Non-raft fractions 8-11 were collected in the density range $1.130 \sim 1.180 \mathrm{~g} / \mathrm{ml}$.

\section{Tube-gel protein digestion}

A Tube-Gel digestion method has been successfully used for high throughput analysis of membrane proteins and proven to be compatible with detergents in protein samples [15]. In these experiments, fraction 3 of the sucrose gradient was used as the lipid raft fraction. The raft fraction was directly incorporated into a polyacrylamide gel matrix as follows: $100 \mu \mathrm{l}$ of the raft solution, $25 \mu \mathrm{l}$ of acrylamide solution $(40 \%, 29: 1), 1.0 \mu \mathrm{l}$ of $10 \%$ SDS, $0.5 \mu \mathrm{l}$ of $10 \%$ ammonium persulfate, and $0.1 \mu$ l of TEMED were mixed in a $0.5 \mathrm{ml}$ Eppendorf tube. The co-polymerization reaction was carried out for $30 \mathrm{~min}$ at room temperature. Post-polymerization, no liquid was extruded from the tube-gel, indicating that all of the materials were trapped in the gel matrix. The gel block was removed, cut into small pieces, and washed five times with $50 \%$ acetonitrile $(\mathrm{v} / \mathrm{v})$ in $25 \mathrm{mM}$ ammonium bicarbonate for $15 \mathrm{~min}$, using sonication and agitation. The gel pieces were dried using a SpeedVac, subjected to in-gel digestion using $100 \mu \mathrm{l}$ of $10 \mathrm{ng} / \mu \mathrm{l}$ trypsin dissolved in $25 \mathrm{mM}$ AMBIC and incubated at $37^{\circ} \mathrm{C}$ overnight. Peptides were then extracted from the gel using $500 \mu \mathrm{l}$ of $0.1 \%$ formic acid in MS-grade water followed by 2 extractions with the same volume of $0.1 \%$ formic acid in $70 \%$ acetonitrile. Corresponding fractions were combined and dried using a SpeedVac. The dried samples were resuspended in $6 \mathrm{M}$ guanidine-hydrochloride and $5 \mathrm{mM}$ potassium phosphate, $\mathrm{pH}$ 6.0, purified using C-18 zip-tips from Millipore Corp., and subjected to nanospray LC-MS/MS analysis. This protocol is referred to as TubeGeLC-MS/MS.

Alternatively, lipid raft proteins were digested using an established protocol with some minor modification by 1D electrophoresis coupled with nanospray LC-MS/MS (GeLC-MS/MS) [72]. Rather than conventional SDSPAGE separation and multiple LC-MS/MS analyses, proteins in $100 \mu \mathrm{l}$ of raft fractions, were first separated on $6 \%$ SDS-PAGE gels, long enough for the protein mixtures to penetrate the separation gel and then stained with silver. The stained areas of the gel containing the complex mixture of proteins were excised, digested with trypsin and applied to the nanospray LC-MS/MS to analyze raft proteome as described above.

\section{Nanospray LC-MSIMS spectrometry and data Analysis}

Automated nanospray liquid chromatography tandem mass spectrometry (nanospray LC-MS/MS) was performed using an LTQ-LC/MS from ThermoFisher Scientific. Peptide mixtures were separated using a C18 reverse phase column $(0.75-\AA$ internal diameter at a flow rate of $1 \mu \mathrm{l} / \mathrm{min}$ ) in line with the mass spectrometer. The mobile phases consisted of $0.1 \%$ formic acid containing $5 \%$ acetonitrile (A) and $0.1 \%$ formic acid in 95\% acetonitrile (B), respectively. A 260-min linear gradient was typically used.

The MS data obtained were searched using the SEQUEST algorithm against the UniProt Rodent database v49.1. The search was limited only to tryptic peptides, and identifications were filtered from the search results using the Epitomize program [74]. Epitomize reads all the SEQUEST.out 
files in a directory, filters the files based on user-defined levels of Xcorr, and outputs the proteins identified. The Xcorr versus charge state filter used was set to Xcorr values of $1.8,2.3$ and 3.0 for charge states $+1,+2$ and +3 , respectively. These filter values are similar to others previously reported for SEQUEST analyses [75]. Protein hits that passed the filter were annotated using the generic Gene Ontology (GO) slim. All proteins were identified by two or more peptides, and those identified with single peptide were included in the analysis if identified in two or more scans. Finally, the peptides listed were manually verified for correct identification by comparing the experimental spectra with the theoretical band ion spectra. Quantitative analyses were done using the open-source software program ZoomQuant, which provides a validation and a quantization platform for protein mass spectrometry $[74,76]$.

\section{Biochemical analysis of lipids in gradient fractions}

Sterol composition in each of the 12 fractions was quantitatively determined by gas chromatography/mass spectroscopy (GC/MS). An aliquot of ethanol containing the internal standard $5 \alpha$-cholestane $(25 \mu \mathrm{g})$ was added to each sample tube, and samples were hydrolyzed at $50^{\circ} \mathrm{C}$ in ethanol containing $1 \mathrm{M} \mathrm{NaOH}$ for 1 hour. Sterols were extracted in hexane (final volume $30 \mathrm{ml}$ ), dried under nitrogen, and derivatized with HMDS-TMCS. GC-MS analysis was performed using a Focus DSQ system (ThermoFisher Scientific). The trimethylsilyl-derived sterols were separated on a TR-35MS capillary column $(35 \mathrm{~m} \times$ $0.25 \mathrm{~mm}$ internal diameter $\times 0.25 \mu \mathrm{m}$ film) with helium as the carrier gas at the rate of $1.8 \mathrm{ml} / \mathrm{min}$. The temperature program was $150^{\circ} \mathrm{C}$ for 1 minute, followed by increases of $20^{\circ} \mathrm{C} / \mathrm{min}$ up to $310^{\circ} \mathrm{C}$, which was then held for 6 minutes. The injector was operated in the splitless mode at $250^{\circ} \mathrm{C}$. Standard curves were generated by MS analysis of various amounts of each sterol. The contents of sphingomyelin (SM), ceramide (Cer) in each of the 12 fractions was quantitatively determined by LC/ESI/MS/ MS on a Thermo Finnigan TSQ 7000 triple quadrupole mass spectrometer, operating in a Multiple Reaction Monitoring (MRM) positive ionization mode, as described previously [77].

\section{SDSIPAGE and immunoblots}

A $30 \mu \mathrm{l}$ aliquot of each fraction from the sucrose gradient was analyzed by SDS/PAGE on 10 or $12 \%(w / v)$ acrylamide gels. Separated proteins were transferred to nitrocellulose membranes for immunoblotting analyses. Membranes were blocked in $5 \%(\mathrm{w} / \mathrm{v})$ non-fat milk in TBS-Tween [0.05\% (w/v) Tween 20 in $10 \mathrm{mM}$ Tris/100 $\mathrm{mM} \mathrm{NaCl}, \mathrm{pH} 7.5]$, and then incubated with the primary antibodies of choice. Membranes were subsequently incubated with HRP-conjugated second antibodies, and specific interactions were revealed using the ECL ${ }^{\oplus}$ (Enhanced
Chemiluminescence) detection system (Amersham, CA, USA).

\section{Competing interests}

The author(s) declare that they have no competing interests.

\section{Authors' contributions}

$\mathrm{HY}$ and BW conceived of the study and designed the experiments. HY, ML, and GST carried out the experiments. HY, BW, BH and SBP analyzed the data and prepared the manuscript. SBP supervised and coordinated the project and HY and SBP obtained funding for this project. HY and SBP wrote the manuscript, and all authors read and approved the final manuscript.

\section{Acknowledgements}

We thank Yanhong Cai for her technical services and assistance with the animal husbandry. The authors thank the members of the Protein Core of Medical College of Wisconsin for the proteomic Service. We also thank Dr. Michael Olivier for critically reading this manuscript. This research was supported by Biomedical Research Grant RG-I I3 II-M from the American Lung Association (HY) and by PHS grant HL68660 from the National Heart, Blood and Lung Institute, NIH (SBP). This work also was supported in part by the NHLBI Proteomics Center contract NIH-NOI HV-28I82.

\section{References}

I. Brown DA: Lipid rafts, detergent-resistant membranes, and raft targeting signals. Physiology (Bethesda) 2006, 2 I :430-439.

2. Allen JA, Halverson-Tamboli RA, Rasenick MM: Lipid raft microdomains and neurotransmitter signalling. Nat Rev Neurosci 2007, 8: | 28-| 40.

3. Pike LJ: Lipid rafts: heterogeneity on the high seas. Biochem J 2004, 378:28I-292.

4. Simons K, Ehehalt R: Cholesterol, lipid rafts, and disease. J Clin Invest 2002, I I 0:597-603.

5. Simons K, Vaz WL: Model systems, lipid rafts, and cell membranes. Annu Rev Biophys Biomol Struct 2004, 33:269-295.

6. Blonder J, Hale ML, Lucas DA, Schaefer CF, Yu LR, Conrads TP, Issaq HJ, Stiles BG, Veenstra TD: Proteomic analysis of detergentresistant membrane rafts. Electrophoresis 2004, 25:1307-1318.

7. Martosella J, Zolotarjova N, Liu H, Moyer SC, Perkins PD, Boyes BE: High recovery HPLC separation of lipid rafts for membrane proteome analysis. J Proteome Res 2006, 5:|30I-I312.

8. Magee Al, Parmryd I: Detergent-resistant membranes and the protein composition of lipid rafts. Genome Biol 2003, 4:234.

9. MacLellan DL, Steen H, Adam RM, Garlick M, Zurakowski D, Gygi SP Freeman MR, Solomon KR: A quantitative proteomic analysis of growth factor-induced compositional changes in lipid rafts of human smooth muscle cells. Proteomics 2005, 5:4733-4742.

10. Elortza F, Nuhse TS, Foster LJ, Stensballe A, Peck SC, Jensen ON: Proteomic analysis of glycosylphosphatidylinositol-anchored membrane proteins. Mol Cell Proteomics 2003, 2:1261-1270.

II. Foster LJ, De Hoog CL, Mann M: Unbiased quantitative proteomics of lipid rafts reveals high specificity for signaling factors. Proc Natl Acad Sci U S A 2003, 100:5813-5818.

12. Gupta N, Wollscheid B, Watts JD, Scheer B, Aebersold R, DeFranco $A L$ : Quantitative proteomic analysis of $B$ cell lipid rafts reveals that ezrin regulates antigen receptor-mediated lipid raft dynamics. Nat Immunol 2006, 7:625-633.

13. Jia JY, Lamer S, Schumann M, Schmidt MR, Krause E, Haucke V: Quantitative proteomics analysis of detergent-resistant membranes from chemical synapses: evidence for cholesterol as spatial organizer of synaptic vesicle cycling. Mol Cell Proteomics 2006, 5:2060-207I. 
4. Sprenger RR, Horrevoets A): Proteomic study of caveolae and rafts isolated from human endothelial cells. Methods Mol Biol 2007, 357:199-213.

15. Lu X, Zhu H: Tube-gel digestion: a novel proteomic approach for high throughput analysis of membrane proteins. Mol Cell Proteomics 2005, 4:1948-1958.

16. Ishmael JE, Safic M, Amparan D, Vogel WK, Pham T, Marley K, Filtz TM, Maier CS: Nonmuscle myosins II-B and Va are components of detergent-resistant membrane skeletons derived from mouse forebrain. Brain Res 2007, I I 43:46-59.

17. Kim KB, Lee JW, Lee CS, Kim BW, Choo HJ, Jung SY, Chi SG, Yoon YS, Yoon G, Ko YG: Oxidation-reduction respiratory chains and ATP synthase complex are localized in detergent-resistant lipid rafts. Proteomics 2006, 6:2444-2453

18. Kisby GE, Standley M, Park T, Olivas A, Fei S, Jacob T, Reddy A, Lu X Pattee P, Nagalla SR: Proteomic analysis of the genotoxicant methylazoxymethanol (MAM)-induced changes in the developing cerebellum. I Proteome Res 2006, 5:2656-2665.

19. Sheikh AM, Barrett C, Villamizar N, Alzate O, Miller S, Shelburne J, Lodge A, Lawson J, Jaggers J: Proteomics of cerebral injury in a neonatal model of cardiopulmonary bypass with deep hypothermic circulatory arrest. J Thorac Cardiovasc Surg 2006, I 32:820-828.

20. Spitzer AR, Chace D: Mass spectrometry in neonatal medicine and clinical diagnosis--the [corrected] potential use of mass spectrometry in neonatal brain [corrected] monitoring. Clin Perinatol 2006, 33:729-44, viii.

21. Yang ZJ, Appleby VJ, Coyle B, Chan WI, Tahmaseb M, Wigmore PM, Scotting PJ: Novel strategy to study gene expression and function in developing cerebellar granule cells. J Neurosci Methods 2004, I 32: 149-160.

22. Kovacs WJ, Shackelford JE, Tape KN, Richards MJ, Faust PL, Fliesler SJ, Krisans SK: Disturbed cholesterol homeostasis in a peroxisome-deficient PEX2 knockout mouse model. Mol Cell Biol 2004, 24: I-13.

23. Edison $R$, Muenke $M$ : The interplay of genetic and environmental factors in craniofacial morphogenesis: holoprosencephaly and the role of cholesterol. Congenit Anom (Kyoto) 2003, 43: I-2 I.

24. Nissenkorn A, Michelson M, Ben-Zeev B, Lerman-Sagie T: Inborn errors of metabolism: a cause of abnormal brain development. Neurology 2001, 56:1265-1272.

25. FitzPatrick DR, Keeling JW, Evans MJ, Kan AE, Bell JE, Porteous ME, Mills K, Winter RM, Clayton PT: Clinical phenotype of desmosterolosis. Am J Med Genet 1998, 75: |45-I52.

26. Opitz JM, de la Cruz F: Cholesterol metabolism in the RSH/ Smith-Lemli-Opitz syndrome: summary of an NICHD conference. Am J Med Genet 1994, 50:326-338.

27. Powers JM, Tummons RC, Moser AB, Moser HW, Huff DS, Kelley RI: Neuronal lipidosis and neuroaxonal dystrophy in cerebrohepato-renal (Zellweger) syndrome. Acta Neuropathol (Berl) 1987, 73:333-343.

28. Li N, Shaw AR, Zhang N, Mak A, Li L: Lipid raft proteomics: analysis of in-solution digest of sodium dodecyl sulfate-solubilized lipid raft proteins by liquid chromatography-matrixassisted laser desorption/ionization tandem mass spectrometry. Proteomics 2004, 4:3 I56-3 I66.

29. Old WM, Meyer-Arendt K, Aveline-Wolf L, Pierce KG, Mendoza A, Sevinsky JR, Resing KA, Ahn NG: Comparison of label-free methods for quantifying human proteins by shotgun proteomics. Mol Cell Proteomics 2005, 4:1487-I502.

30. Mukherjee A, Arnaud L, Cooper JA: Lipid-dependent recruitment of neuronal Src to lipid rafts in the brain. I Biol Chem 2003, 278:40806-408|4

31. Melkonian KA, Ostermeyer AG, Chen JZ, Roth MG, Brown DA: Role of lipid modifications in targeting proteins to detergentresistant membrane rafts. Many raft proteins are acylated, while few are prenylated. I Biol Chem 1999, 274:3910-3917.

32. Santoni V, Molloy M, Rabilloud T: Membrane proteins and proteomics: un amour impossible? Electrophoresis 2000 2 I: 1054-1070

33. Blonder J, Chan KC, Issaq HJ, Veenstra TD: Identification of membrane proteins from mammalian cell/tissue using methanolfacilitated solubilization and tryptic digestion coupled with 2D-LC-MS/MS. Nat Protoc 2006, 1:2784-2790.

34. States DJ, Omenn GS, Blackwell TW, Fermin D, Eng J, Speicher DW Hanash SM: Challenges in deriving high-confidence protein identifications from data gathered by a HUPO plasma proteome collaborative study. Nat Biotechnol 2006, 24:333-338.

35. Elmariah SB, Hughes EG, Oh EJ, Balice-Gordon RJ: Neurotrophin signaling among neurons and glia during formation of tripartite synapses. Neuron Glia Biol 2005, I: I- I I.

36. Foty RA, Steinberg MS: Cadherin-mediated cell-cell adhesion and tissue segregation in relation to malignancy. Int J Dev Bio 2004, 48:397-409.

37. Scheiffele $P$ : Cell-cell signaling during synapse formation in the CNS. Annu Rev Neurosci 2003, 26:485-508.

38. Fetissov SO, Bergstrom U, Johansen JE, Hokfelt T, Schalling M, Ranscht B: Alterations of arcuate nucleus neuropeptidergic development in contactin-deficient mice: comparison with anorexia and food-deprived mice. Eur J Neurosci 2005, 22:3217-3228.

39. Yang JW, Rodrigo R, Felipo V, Lubec G: Proteome analysis of primary neurons and astrocytes from rat cerebellum. I Proteome Res 2005, 4:768-788.

40. Dremina ES, Sharov VS, Schoneich C: Protein tyrosine nitration in rat brain is associated with raft proteins, flotillin-I and alpha-tubulin: effect of biological aging. J Neurochem 2005, 93:|262-|27|.

4I. Head BP, Patel HH, Roth DM, Murray F, Swaney IS, Niesman IR, Farquhar MG, Insel PA: Microtubules and actin microfilaments regulate lipid raft/caveolae localization of adenylyl cyclase signaling components. J Biol Chem 2006, 28 I:2639l-26399.

42. Chen S, Bawa D, Besshoh S, Gurd JW, Brown IR: Association of heat shock proteins and neuronal membrane components with lipid rafts from the rat brain. I Neurosci Res 2005, $8 \mathrm{I}: 522-529$

43. Say $\mathrm{YH}$, Hooper NM: Contamination of nuclear fractions with plasma membrane lipid rafts. Proteomics 2007, 7: I059-1064.

44. Bae TJ, Kim MS, Kim JW, Kim BW, Choo HJ, Lee JW, Kim KB, Lee CS, Kim JH, Chang SY, Kang CY, Lee SW, Ko YG: Lipid raft proteome reveals ATP synthase complex in the cell surface. Proteomics 2004, 4:3536-3548.

45. Igbavboa U, Eckert GP, Malo TM, Studniski AE, Johnson LN, Yamamoto N, Kobayashi M, Fujita SC, Appel TR, Muller WE, Wood WG, Yanagisawa K: Murine synaptosomal lipid raft protein and lipid composition are altered by expression of human apoE 3 and 4 and by increasing age. J Neurol Sci 2005, 229-230:225-232.

46. Thouvenot E, Lafon-Cazal M, Demettre E, Jouin P, Bockaert J, Marin $P$ : The proteomic analysis of mouse choroid plexus secretome reveals a high protein secretion capacity of choroidal epithelial cells. Proteomics 2006, 6:594|-5952.

47. Pelkmans L, Puntener D, Helenius A: Local actin polymerization and dynamin recruitment in SV40-induced internalization of caveolae. Science 2002, 296:535-539.

48. Chang L, Goldman RD: Intermediate filaments mediate cytoskeletal crosstalk. Nat Rev Mol Cell Biol 2004, 5:60I-6I3.

49. Franzen R, Tanner SL, Dashiell SM, Rottkamp CA, Hammer JA, Quarles RH: Microtubule-associated protein IB: a neuronal binding partner for myelin-associated glycoprotein. J Cell Biol 200I, I 55:893-898.

50. Fu H, Subramanian RR, Masters SC: 14-3-3 proteins: structure, function, and regulation. Annu Rev Pharmacol Toxicol 2000 , 40:617-647

5I. Watson K, Edwards RJ, Shaunak S, Parmelee DC, Sarraf C, Gooderham NJ, Davies DS: Extra-nuclear location of histones in activated human peripheral blood lymphocytes and cultured $\mathrm{T}$. cells. Biochem Pharmacol 1995, 50:299-309.

52. Lawen A, Ly JD, Lane DJ, Zarschler K, Messina A, De Pinto V: Voltage-dependent anion-selective channel I (VDACI)--a mitochondrial protein, rediscovered as a novel enzyme in the plasma membrane. Int J Biochem Cell Biol 2005, 37:277-282.

53. Andreev VP, Li L, Cao L, Gu Y, Rejtar T, Wu SL, Karger BL: A New Algorithm Using Cross-Assignment for Label-Free Quantitation with LC-LTQ-FT MS. J Proteome Res 2007

54. Wienkoop S, Larrainzar E, Niemann M, Gonzalez EM, Lehmann U, Weckwerth W: Stable isotope-free quantitative shotgun proteomics combined with sample pattern recognition for rapid diagnostics. J Sep Sci 2006, 29:2793-280I.

55. Le Bihan T, Goh T, Stewart, Salter AM, Bukhman YV, Dharsee M, Ewing R, Wisniewski JR: Differential analysis of membrane proteins in mouse fore- and hindbrain using a label-free approach. J Proteome Res 2006, 5:270I-27I0. 
56. Wang G, Wu WW, Zeng W, Chou CL, Shen RF: Label-free protein quantification using LC-coupled ion trap or FT mass spectrometry: Reproducibility, linearity, and application with complex proteomes. J Proteome Res 2006, 5: I 2 I 4- 223.

57. Ru QC, Zhu LA, Silberman J, Shriver CD: Label-free semiquantitative peptide feature profiling of human breast cancer and breast disease sera via two-dimensional liquid chromatography-mass spectrometry. Mol Cell Proteomics 2006, 5: I 095-I I04.

58. Cui XY, Hu QD, Tekaya M, Shimoda Y, Ang BT, Nie DY, Sun L, Hu WP, Karsak M, Duka T, Takeda Y, Ou LY, Dawe GS, Yu FG, Ahmed S, Jin LH, Schachner M, Watanabe K, Arsenijevic Y, Xiao ZC: NB-3/ Notch I pathway via Deltex I promotes neural progenitor cell differentiation into oligodendrocytes. J Biol Chem 2004, 279:25858-25865.

59. Brady ST, Lasek RJ: Nerve-specific enolase and creatine phosphokinase in axonal transport: soluble proteins and the axoplasmic matrix. Cell 198I, 23:5I5-523.

60. Deininger SO, Rajendran L, Lottspeich F, Przybylski M, Illges H, Stuermer CA, Reuter A: Identification of teleost Thy-I and association with the microdomain/lipid raft reggie proteins in regenerating CNS axons. Mol Cell Neurosci 2003, 22:544-554.

61. Hu QD, Ang BT, Karsak M, Hu WP, Cui XY, Duka T, Takeda Y, Chia W, Sankar N, Ng YK, Ling EA, Maciag T, Small D, Trifonova R, Kopan R, Okano H, Nakafuku M, Chiba S, Hirai H, Aster JC, Schachner M, Pallen CJ, Watanabe K, Xiao ZC: F3/contactin acts as a functional ligand for Notch during oligodendrocyte maturation. Cell 2003, II5:163-175

62. Guirland C, Suzuki S, Kojima M, Lu B, Zheng JQ: Lipid rafts mediate chemotropic guidance of nerve growth cones. Neuron 2004, 42:51-62.

63. Kashihara M, Miyata S, Kumanogoh H, Funatsu N, Matsunaga W, Kiyohara T, Sokawa Y, Maekawa S: Changes in the localization of NAP-22, a calmodulin binding membrane protein, during the development of neuronal polarity. Neurosci Res 2000, 37:315-325.

64. Leshchyns'ka I, Sytnyk V, Morrow JS, Schachner M: Neural cell adhesion molecule (NCAM) association with PKCbeta2 via betal spectrin is implicated in NCAM-mediated neurite outgrowth. J Cell Biol 2003, 16 I:625-639.

65. Maekawa S, Morii H, Kumanogoh H, Sano M, Naruse Y, Sokawa $Y$, Mori N: Localization of neuronal growth-associated, microtubule-destabilizing factor SCG 10 in brain-derived raft membrane microdomains. J Biochem (Tokyo) 200I, I 29:69I-697.

66. Miyata S, Funatsu N, Matsunaga W, Kiyohara T, Sokawa Y, Maekawa S: Expression of the IgLON cell adhesion molecules Kilon and OBCAM in hypothalamic magnocellular neurons. J Comp Neurol 2000, 424:74-85.

67. Roussel G, Nussbaum F, Schoentgen F, Jolles P, Nussbaum JL: Immunological investigation of a $2 \mathrm{I}$-kilodalton cytosolic basic protein in rat brain. Dev Neurosci 1988, 10:65-74.

68. Schaeren-Wiemers N, Bonnet A, Erb M, Erne B, Bartsch U, Kern F, Mantei N, Sherman D, Suter U: The raft-associated protein MAL is required for maintenance of proper axon--glia interactions in the central nervous system. J Cell Biol 2004, 166:73 I-742.

69. Schlicht K, Buttner A, Siedler F, Scheffer B, Zill P, Eisenmenger W, Ackenheil M, Bondy B: Comparative proteomic analysis with postmortem prefrontal cortex tissues of suicide victims versus controls. J Psychiatr Res 2007, 41:493-50I.

70. Yanagisawa $M$, Nakamura $K$, Taga $T$ : Roles of lipid rafts in integrin-dependent adhesion and gp 130 signalling pathway in mouse embryonic neural precursor cells. Genes Cells 2004, 9:80I-809.

71. Yang JW, Suder P, Silberring J, Lubec G: Proteome analysis of mouse primary astrocytes. Neurochem Int 2005, 47:159- 172.

72. Schirle M, Heurtier MA, Kuster B: Profiling core proteomes of human cell lines by one-dimensional PAGE and liquid chromatography-tandem mass spectrometry. Mol Cell Proteomics 2003, 2: I 297-1305.

73. Yu H, Li M, Tint GS, Chen J, Xu G, Patel SB: Selective reconstitution of liver cholesterol biosynthesis promotes lung maturation but does not prevent neonatal lethality in Dhcr7 null mice. BMC Dev Biol 2007, 7:27.

74. Hicks WA, Halligan BD, Slyper RY, Twigger SN, Greene AS, Olivier $M$ : Simultaneous quantification and identification using 180 labeling with an ion trap mass spectrometer and the analysis software application "ZoomQuant". I Am Soc Mass Spectrom 2005, 16:916-925.

75. Mirza SP, Halligan BD, Greene AS, Olivier M: An improved method for the analysis of membrane proteins by mass spectrometry. Physiol Genomics 2007.

76. Halligan BD, Slyper RY, Twigger SN, Hicks W, Olivier M, Greene AS: ZoomQuant: an application for the quantitation of stable isotope labeled peptides. J Am Soc Mass Spectrom 2005, 16:302-306.

77. Bielawski J, Szulc ZM, Hannun YA, Bielawska A: Simultaneous quantitative analysis of bioactive sphingolipids by high-performance liquid chromatography-tandem mass spectrometry. Methods 2006, 39:82-91.
Publish with Bio Med Central and every scientist can read your work free of charge

"BioMed Central will be the most significant development for disseminating the results of biomedical research in our lifetime. "

Sir Paul Nurse, Cancer Research UK

Your research papers will be:

- available free of charge to the entire biomedical community

- peer reviewed and published immediately upon acceptance

- cited in PubMed and archived on PubMed Central

- yours - you keep the copyright 